\title{
Transcriptome and excretory-secretory proteome of infective-stage larvae of the nematode Gnathostoma spinigerum reveal potential immunodiagnostic targets for development
}

\author{
Supaporn Nuamtanong ${ }^{1}$, Onrapak Reamtong ${ }^{2}$, Orawan Phuphisut ${ }^{1}$, Palang Chotsiri ${ }^{3}$, Preeyarat Malaithong ${ }^{1}$, \\ Paron Dekumyoy ${ }^{1}$, and Poom Adisakwattana ${ }^{1, *}$ \\ ${ }^{1}$ Department of Helminthology, Faculty of Tropical Medicine, Mahidol University, Bangkok 10400, Thailand \\ 2 Department of Molecular Tropical Medicine and Genetics, Faculty of Tropical Medicine, Mahidol University, Bangkok 10400, Thailand \\ 3 Mahidol-Oxford Tropical Medicine Research Unit, Mahidol University, Bangkok 10400, Thailand
}

Received 18 December 2018, Accepted 16 May 2019, Published online 5 June 2019

\begin{abstract}
Background: Gnathostoma spinigerum is a harmful parasitic nematode that causes severe morbidity and mortality in humans and animals. Effective drugs and vaccines and reliable diagnostic methods are needed to prevent and control the associated diseases; however, the lack of genome, transcriptome, and proteome databases remains a major limitation. In this study, transcriptomic and secretomic analyses of advanced third-stage larvae of G. spinigerum (aL3Gs) were performed using next-generation sequencing, bioinformatics, and proteomics. Results: An analysis that incorporated transcriptome and bioinformatics data to predict excretory-secretory proteins (ESPs) classified 171 and 292 proteins into classical and non-classical secretory groups, respectively. Proteins with proteolytic (metalloprotease), cell signaling regulatory (i.e., kinases and phosphatase), and metabolic regulatory function (i.e., glucose and lipid metabolism) were significantly upregulated in the transcriptome and secretome. A two-dimensional (2D) immunomic analysis of aL3Gs-ESPs with G. spinigerum-infected human sera and related helminthiases suggested that the serine protease inhibitor (serpin) was a promising antigenic target for the further development of gnathostomiasis immunodiagnostic methods. Conclusions: The transcriptome and excretory-secretory proteome of aL3Gs can facilitate an understanding of the basic molecular biology of the parasite and identifying multiple associated factors, possibly promoting the discovery of novel drugs and vaccines. The 2D-immunomic analysis identified serpin, a protein secreted from aL3Gs, as an interesting candidate for immunodiagnosis that warrants immediate evaluation and validation.
\end{abstract}

Key words: Gnathostoma spinigerum, Advanced third stage larva, Transcriptomics, Excretory-secretory proteins, Proteomics, Serpin, Immunodiagnosis.

\begin{abstract}
Résumé - Le transcriptome et le protéome excréto-sécrétoire des larves au stade infectant du nématode Gnathostoma spinigerum révèlent des cibles immunodiagnostiques potentielles à développer. Contexte : Gnathostoma spinigerum est un nématode parasite nuisible qui provoque une morbidité et une mortalité graves chez les humains et les animaux. Des médicaments et des vaccins efficaces et des méthodes de diagnostic fiables sont nécessaires pour prévenir et contrôler les maladies associées. Cependant, l'absence de bases de données sur le génome, le transcriptome et le protéome reste une limitation majeure. Dans cette étude, des analyses transcriptomiques et sécrétomiques de larves avancées au troisième stade de G. spinigerum (aL3G) ont été effectuées par des méthodes de nouvelle génération de séquençage, bioinformatique et protéomique. Résultats : Une analyse incorporant des données de transcriptome et de bioinformatique pour prédire les protéines excrétosécrétoires (ESP) a classé respectivement 171 et 292 protéines en groupes de sécrétions classiques et non classiques. Les protéines protéolytiques (métalloprotéases), régulatrices de la signalisation cellulaire (kinases et phosphatases) et régulatrices métaboliques (métabolisme du glucose et des lipides) étaient régulées à la hausse dans le transcriptome et le sécrétome. Une analyse immunomique bidimensionnelle (2D) des aL3Gs-ESP avec des sérums humains infectés par G. spinigerum et des helminthiases apparentées a suggéré que l'inhibiteur de la sérine protéase (serpine) était une cible antigénique prometteuse pour le développement ultérieur de méthodes immunodiagnostiques de la gnathostomose. Conclusions : Le transcriptome et le protéome excréto-sécrétoire des aL3G peuvent faciliter la compréhension de la biologie moléculaire de base du parasite et l'identification de
\end{abstract}

*Corresponding author: poom. adi@mahidol. ac. th

This is an Open Access article distributed under the terms of the Creative Commons Attribution License (http://creativecommons.org/licenses/by/4.0), which permits unrestricted use, distribution, and reproduction in any medium, provided the original work is properly cited. 
multiples facteurs associés, favorisant éventuellement la découverte de nouveaux médicaments et vaccins. L'analyse 2D-immunomique a identifié la serpine, une protéine sécrétée par les aL3G, comme un candidat intéressant pour l'immunodiagnostic, qui mérite une évaluation et une validation immédiates.

\section{Introduction}

Gnathostomiasis is an important foodborne parasitic zoonosis caused by nematodes of the genus Gnathostoma Owen, 1836. Until now, 23 species have been described in this genus that distribute in various regions of the world $[10,53]$. Of these, there are six species including G. spinigerum, G. binucleatum, G. doloresi, G. hispidum, G. malaysiae, and G. nipponicum that have been reported to infect humans [10]. Outbreaks of human gnathostomiasis have frequently occurred in Asia and Central America [1, 17], and sporadic cases reported in several countries have been associated with travelers who returned home after visiting endemic areas [31, 43]. In Southeast Asia, G. spinigerum is considered a major gnathostomiasis-causing species in humans. G. spinigerum is classified in Phylum Nematoda, Order Rhabditida, Family Gnathostomatidae, and Genus Gnathostoma. Humans are infected by consumption of raw or improperly cooked fishes, amphibians, and eels that harbor infective (advanced third-stage) larvae. Among these, swamp eels (Monopterus albus) are a common source of human gnathostomiasis [16].

Clinical manifestations observed during G. spinigerum infection include intermittent subcutaneous or cutaneous migratory swelling with peripheral eosinophilia. The migration of parasites to visceral organs, such as the brain, spinal cord, and eyes, can potentially cause severe diseases [7, 15, 65]. Clinical signs and symptoms, with a history of ingesting raw or improperly cooked secondary intermediate or paratenic hosts, have been used to guide the diagnosis of gnathostomiasis. Alternatively, immunodiagnostic methods have been developed and used to support the diagnosis of this disease. Currently, immunoblotting to detect the 24-kDa crude worm antigen (CWA) expressed by advanced third-stage larvae of G. spinigerum (aL3Gs) is a reliable immunodiagnostic technique that provides high sensitivity and specificity rates $(80 \%-90 \%)[28,35]$. However, the identification of additional diagnostic candidates may help to increase the reliability and effectiveness of immunodiagnosis.

Parasitic helminths release excretory-secretory products (ESPs) that are indispensable to nutrient uptake, tissue penetration, immune invasion, host-parasite interactions, and other processes in all life stages [13, 57]. Moreover, ESPs have been used as diagnostic tools as they are released into the blood circulation and can induce antibody production in the infected host. Accordingly, ESPs could be used to develop immunoassays to detect circulating antigens or antibodies [3, 57]. In the context of a $G$. spinigerum infection, the identification of a specific IgE against ESPs from aL3Gs could improve the power of diagnostic methods and yield improved sensitivity and specificity relative to CWA [54]. In a mouse model, an early infection could be identified by using a two-site enzyme-linked immunosorbent assay to detect circulating aL3G antigens [40]. However, information regarding ESPs of aL3Gs and the identification of novel candidates for immunodiagnostic methods remain limited and require further analysis.

Therefore, this study aimed to use an integrative approach to identify a novel target derived from ESPs of aL3Gs. A global cDNA-transcribed library of aL3Gs was constructed using next-generation sequencing (NGS), and potential ESPs were predicted through a bioinformatics analysis. A two-dimensional (2D) gel electrophoresis (2DE) with an incorporated immunomic assay was performed. Subsequently, the peptide masses were evaluated using mass spectrometry, and the in-house cDNA-transcribed library was used to search for a specific protein. In the future, the study findings may have a remarkable impact on the development of reliable immunodiagnostics, as well as novel therapies against gnathostomiasis.

\section{Materials and methods Parasite}

The aL3Gs were obtained from the livers of naturally infected eels using an acid-pepsin digestion technique [44]. In summary, the eel livers were chopped, digested in $1 \%$ acidpepsin at $37{ }^{\circ} \mathrm{C}$ for $2 \mathrm{~h}$ in a water bath with frequent stirring, and washed several times with tap water via a simple sedimentation technique. The worms were isolated and identified using a dissecting microscope and washed several times with normal saline solution $(0.85 \% \mathrm{NaCl})$, followed by distilled water. Approximately 20 worms were pooled into a microfuge tube and stored at $-80{ }^{\circ} \mathrm{C}$ until further use.

\section{Transcriptome analysis using the Illumina HiSeq platform}

Total RNA was extracted from aL3Gs using TRIZOL ${ }^{\mathrm{TM}}$ reagent (Invitrogen, Carlsbad, CA, USA) according to the manufacturer's instructions and quantified and qualified using an Agilent 2100 Bioanalyzer (Agilent Technologies, Palo Alto, CA, USA), NanoDrop spectrophotometer (Thermo Fisher Scientific, Inc., Wilmington, DE, USA) (Supplementary Fig. S1), and $1 \%$ agarose gels. One microgram of total RNA with a RIN value $>7$ was used to prepare the library as follows [55]. The library was constructed using the NEBNext ${ }^{\circledR}$ UltraTM RNA Library Prep Kit for Illumina ${ }^{\circledR}$ (New England Biolabs [NEB], Ipswich, MA, USA) according to the manufacturer's protocol. Poly(A) mRNA isolation was performed using the NEBNext Poly(A) mRNA Magnetic Isolation Module (NEB). mRNA fragmentation and priming were performed using the NEBNext First Strand Synthesis Reaction Buffer and NEBNext Random Primers. First-strand cDNA was then synthesized from mRNA using ProtoScript II Reverse Transcriptase, and secondstrand cDNA was synthesized using Second Strand Synthesis Enzyme Mix. Double-stranded cDNA was purified using 
AxyPrep Mag PCR Clean-up (Axygen Biosciences, Union City, CA, USA) and treated with End Prep Enzyme Mix to repair both ends and add a dA-tail in a single reaction, followed by T-A ligation to add adaptors to both ends. The adaptorligated DNA fragments were subjected to size selection using AxyPrep Mag PCR Clean-up (Axygen), which recovered fragments measuring approximately $360 \mathrm{bp}$. Each sample was then amplified by PCR for 11 cycles using P5 and P7 primers; both primers carry sequences that can anneal to the flow cell to enable bridge PCR, while the P7 primer carries a six-base index that enables multiplexing. The PCR products were cleaned using AxyPrep Mag PCR Clean-up (Axygen), validated using an Agilent 2100 Bioanalyzer (Agilent Technologies, Palo Alto, CA, USA), and quantified using a Qubit 2.0 Fluorometer (Invitrogen, Carlsbad, CA, USA). Next, libraries with different indices were multiplexed and loaded on an Illumina HiSeq instrument, according to the manufacturer's instructions (Illumina, San Diego, CA, USA). Sequencing was performed using a $2 \times 150$-bp paired-end (PE) configuration; here, image analysis and base calling were conducted on a HiSeq instrument equipped with HiSeq Control Software (HCS) + RTA 2.7 (Illumina).

Sequencing quality was processed according to the following steps: first, the read quality was assessed using FastQC v0.11.5 software. Nucleotide read quality estimates were produced using the PHRED scale. Second, sequencing adapters were trimmed from the raw reads with inexact matches using Trimmomatic v0.32 software; at the Q20 quality level, a maximum of two mismatches were allowed. Third, the first three nucleotides were trimmed from each read. Fourth, low-quality bases less than Q30 from each end were further trimmed using the running average algorithm. Finally, the resulting sequences with lengths of at least $30 \mathrm{bp}$ were selected for the analysis. The quality of the reads was assessed with FastQC v0.11.5 software.

\section{Bioinformatics of the aL3Gs transcriptome}

High-quality sequences (Q30 or higher) were selected for the assembly. The Bridger program, de novo transcriptome assembler, was used to produce contig sequences without reference genome [11]. Subsequently, the assembled contigs were arranged in groups that each contained several tentative transcript variants originating from the same locus.

To annotate the assembled transcripts, two complementary strategies were applied. First, the BLASTX algorithm (BLAST v.2.2.31) [9] was used to align the assembled transcript sequences directly against all Metazoa protein sequences in the UniProt database. Second, each transcript was translated into all possible open reading frames (ORF) using FragGeneScanplus [32], and each ORF was then aligned against the Conserved Domain Database (CDD) using RPS-BLAST (Reverse PositionSpecific BLAST; https://www.ncbi.nlm.nih.gov/Structure/cdd/ wrpsb.cgi) [41]. If the transcripts were not functionally annotated sufficiently well in this step, the best UniProt alignment was selected as representative and was complemented with the best CDD annotation according to the blast Bit score and the $E$-value. A threshold of $E$-value $<10^{-5}$ was applied in functional prediction analysis. Additionally, the transcripts were categorized by homology with conserved domains and with protein families via annotation with the gene ontology (GO) database. The aL3Gs transcripts were then assigned into three GO categories: molecular function, cellular component, and biological process [2].

\section{In silico analysis of Excretory-Secretory Proteins}

Potential ESPs were predicted from the aL3Gs transcriptome using methods published by Garg and Ranganathan [22, 23] and Pan et al. [46], with some modification. In summary, the classifications of all possible proteins $(N=35,850)$ annotated using the CDD database as classical and non-classical secreted proteins were predicted using SignalP 4.1 [5] and SecretomeP 2.0 [4], respectively. TargetP 1.1 was used to predict mitochondrial target signals [21]; THHMM 2.0 was used to predict transmembrane helices [20]; we then used the results of TargetP 1.1 and THHMM 2.0 to exclude mitochondrial and transmembrane proteins from the potential ESPs, respectively. The ESP prediction pipeline is summarized in Supplementary Figure S2. Finally, both potential classical and non-classical ESPs were annotated against the GO database.

\section{Excretory-Secretory Proteome}

ESPs of aL3Gs were prepared by culturing larvae in vitro in RPMI 1640 medium (GE Healthcare Life Sciences, South Logan, UT, USA) supplemented with $1 \times$ penicillin/ streptomycin (Biowest SAS, Nuaillé, France), and $4.5 \mathrm{~g} / \mathrm{L}$ glucose for 6 days. The culture medium was collected every $24 \mathrm{~h}$ and replaced with new medium. Medium collected at each time point was dialyzed against $1 \times \mathrm{PBS}$ for $48 \mathrm{~h}$ at $4{ }^{\circ} \mathrm{C}$ and concentrated using Amicon ${ }^{\circledR}$ Stirred Cells (Merck Millipore, Darmstadt, Germany). The quality of protein at each time point was examined by $12 \%$ SDS-PAGE. The ESPs exhibiting similar patterns as those observed at $24 \mathrm{~h}$, without degradation, were pooled and subjected to a Coomassie Plus ${ }^{\mathrm{TM}}$ Protein Assay (Thermo Fisher Scientific) to determine the protein concentration, followed by storage at $-80{ }^{\circ} \mathrm{C}$.

Ten micrograms of ESPs were separated by $12 \%$ SDSPAGE prior to staining with Coomassie Brilliant Blue G250 solution (Bio-Rad, Hercules, CA, USA). Each gel was cut into 16 rectangles, destained with a destaining solution $[50 \mathrm{mM}$ $\mathrm{NH}_{4} \mathrm{HCO}_{3}, 50 \%(\mathrm{~V} / \mathrm{V})$ acetonitrile $\left.(\mathrm{ACN})\right]$, reduced with 5 $\mathrm{mM}$ dithiothreitol (DTT) (GE Healthcare, UK), and alkylated with $250 \mathrm{mM}$ iodoacetamide (IAM; GE Healthcare, UK). The gel pieces were then incubated in the dark for $30 \mathrm{~min}$ and dehydrated with $200 \mathrm{~mL}$ ACN. The gels were incubated with trypsin (100 ng/mL; Sigma) at $37{ }^{\circ} \mathrm{C}$ overnight to digest the proteins to peptides. These peptides were extracted from the gels using $50 \%(\mathrm{~V} / \mathrm{V}) \mathrm{ACN}$, dried in a vacuum evaporator (Labconco, Kansas City, MO, USA) and resuspended in $0.1 \%$ formic acid. Each peptide suspension was then injected into an Ultimate 3000 nano-liquid chromatography system (Dionex; Surrey, UK) coupled with tandem MS (nanoLC-MS/MS; micrOTOF-Q II, Bruker; Bremen, Germany), and the resulting mass spectra were processed using analysis software (DataAnalysisTM 4.0, Bruker), as described elsewhere [59]. 
Mascot version 2.4.1 (Matrix Science, London, UK) was used to search the .mgf file against our in-house transcriptome database. Missed cleavage was set to 1 . The variable modification setting was cysteine carbamidomethylation and methionine oxidation. Only protein hits from the MASCOT search with $\geq 95 \%$ confidence were reported.

\section{Two-DE and immunomics}

Twenty-five micrograms of ESPs in a $100 \mu \mathrm{L}$ volume were transferred into a microcentrifuge tube; the interfering substance was removed using a 2-D Clean-Up kit (GE Healthcare), according to the manufacturer's instructions. The pellet was resuspended in $125 \mu \mathrm{L}$ of DeStreak rehydration solution containing IPG buffer (0.5\% IPG buffer pH 3-10 NL; GE Healthcare) and then transferred into an IPG strip holder; subsequently, an Immobiline DryStrip pH 3-10 NL, 7 cm (GE Healthcare) was placed face down on the solution. After overlaying cover fluid, the strip was allowed to rehydrate in Ettan IPGphor II under the condition of $50 \mu \mathrm{A} /$ strip and $20^{\circ} \mathrm{C}$ for $14 \mathrm{~h}$, and was then placed face up on an Ettan IPGphor Manifold (GE Healthcare). Electrophoresis was performed using the following running conditions: $0.3 \mathrm{kV} / \mathrm{h}$ for the initial $30 \mathrm{~min}$, followed by a gradient of $0.3 \mathrm{kV} / \mathrm{h}$ for $30 \mathrm{~min}, 4.0 \mathrm{kV} / \mathrm{h}$ for $90 \mathrm{~min}$, and step down and hold at $3.0 \mathrm{kV} / \mathrm{h}$ for $35 \mathrm{~min}$. Subsequent steps, including reduction, alkylation, and SDS-PAGE, were performed as described previously [59]. The protein spots were visualized by staining with Coomassie Brilliant Blue G-250 (CBB) dye.

For immunomics, protein spots in the gels were electrically transferred to PVDF membranes (Pall Corporation, Ann Arbor, MI, USA) and allowed to interact with pooled sera from patients with confirmed helminthic infections, including G. spinigerum, Angiostrongylus cantonensis, cysticercosis, Strongyloides stercoralis, sparganosis, and soil-transmitted helminths (STHs) (five patients per pool). Sera from healthy individuals with no history of infection or relevant signs/symptoms were used as negative controls. The reactive patterns were compared, and protein spots specific to G. spinigerum infection were identified. These spots were excised from a CBB-stained gel, and the proteins were identified using MS, as described above.

\section{Results}

\section{Transcriptome assembly from aL3Gs RNA-Seq data}

An analysis of aL3Gs transcripts conducted using the Illumina HiSeq platform yielded 61,602,864 raw reads. After removing adaptors, undetermined nucleotides, and low-quality reads, 56,710,418 $(92.1 \%)$ clean reads were retrieved. The baseand raw read-qualities from NGS sequencing are shown in Supplementary Figure S3 and Supplementary Table S1, respectively. The high-quality reads were then assembled into contigs. The distribution of contig lengths and densities are shown in Supplementary Figure S4. The clean reads were successfully assembled, which generated 117,204 contigs ranging in size between 201 and 22,386 nucleotides (nt; average $=1200 \mathrm{nt}$ ) (Table 1, Supplementary Table S1). The contigs were then subjected to protein-coding prediction (Supplementary Table S2
Table 1. Statistical summary of the de novo assembled sequences from advanced third-stage Gnathostoma spinigerum larvae (aL3Gs).

\begin{tabular}{ll}
\hline Parameter & Number \\
\hline Sequencing results & \\
$\quad$ Total raw reads & $61,602,864$ \\
Total clean reads & $56,710,418(92.1 \%)$ \\
De novo assembly results & \\
$\quad$ Total number of contigs & 117,204 \\
Average contig length & $1,200 \mathrm{nt}(201-22,386 \mathrm{nt})$ \\
(min-max length) & \\
Total number of splice variant groups & 86,312 \\
Average splice variant per groups & $2.2(1-21)$ \\
(min-max) & \\
Annotations results & $35,850(96.6 \%)$ \\
CDD annotation (\%) & $14,064(37.9 \%)$ \\
UniProt annotation (\%) & $26,259(70.8 \%)$ \\
GO annotation (\%) & $37,099(100.0 \%)$ \\
Total annotation (\%) & \\
With homologues in G. spinigerum & $7,420(20.0 \%)$ \\
Bilateria (\%) & $5,980(16.1 \%)$ \\
Toxocara canis $(\%)$ & $5,238(14.1 \%)$ \\
Ascaris suum (\%) & $1,674(4.5 \%)$ \\
Anisakis simplex (\%) & $1,399(3.7 \%)$ \\
Ascaris lumbricoides (\%) & $986(2.7 \%)$ \\
Enterobius vermicularis $(\%)$ & $26,259(70.8 \%)$ \\
GO function classification (\%) & 11,439 \\
Biological process & 15,358 \\
Cellular component & 19,775 \\
Molecular function & \\
\hline
\end{tabular}

and S3), which yielded 37,099 contigs that could potentially be translated into proteins (Supplementary Table S1). The assembled contigs have been deposited in the Transcriptome Shotgun Assembly (TSA) database under accession number GHIZ00000000.

\section{Functional annotation of aL3Gs transcriptomes}

A functional annotation of all assembled contigs demonstrated that $35,850(96.6 \%)$ and $14,064(37.9 \%)$ protein-coding transcripts were successfully annotated using the UniProt and NCBI Conserved Domains databases (using BLASTX with an $E$-value cut-off $<10^{-5}$ ), respectively. Approximately $78.0 \%$ of the transcripts had an amino acid identity of more than $40 \%$ with orthologs sharing high homology with proteins from nematodes such as Toxocara canis $(16.1 \%)$, Ascaris suum (14.1\%), and Anisakis simplex (5\%), respectively (Supplementary Fig. S5). The distribution of the best sequence alignment identities was based on the BLAST $E$-values and is shown in Supplementary Fig. S6. A gene ontology (GO) annotation was used to predict the protein functional group classifications of the aL3Gs transcripts. Here 26,259 (70.8\%) of the 37,099 $(100 \%)$ assembled transcripts could be successfully assigned into at least one of three GO terms encompassing 60 GO assignments. The first group, "Molecular functions," contained 19,775 transcripts, followed by "Cellular components" and "Biological processes" with 15,358 and 11,439 transcripts, respectively. The predominant terms listed under "Molecular function" were ATP binding (15.0\%), nucleic acid binding 
Classical ESPs

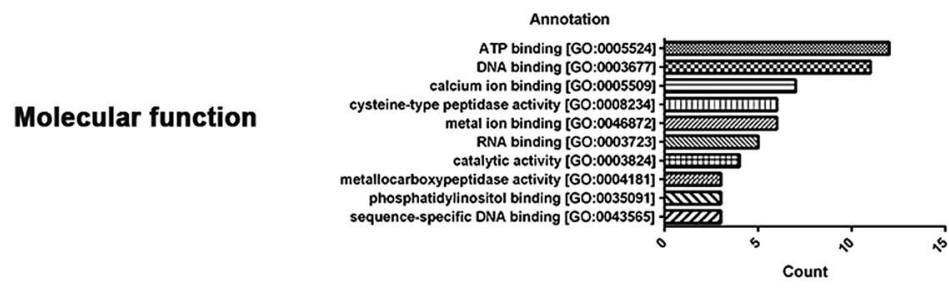

Annotation

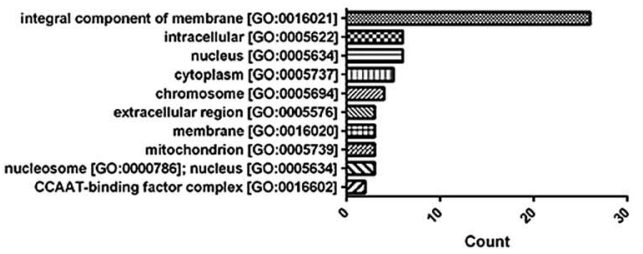

Cellular component

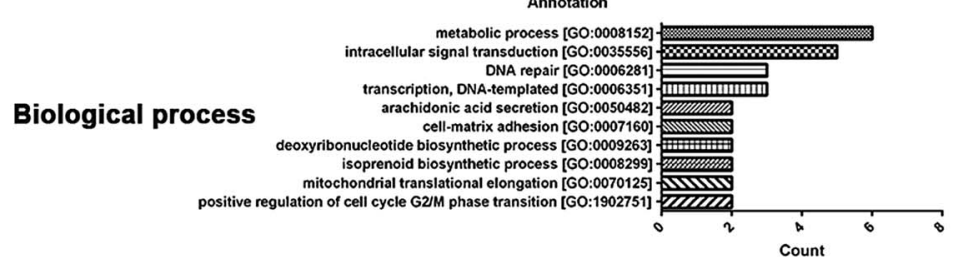

Non-Classical ESPs

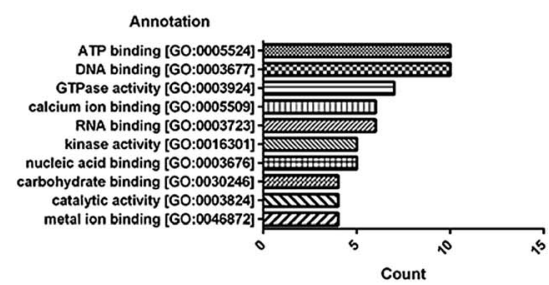

Annotation

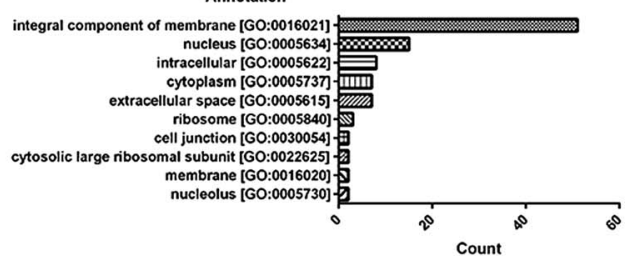

Annotation

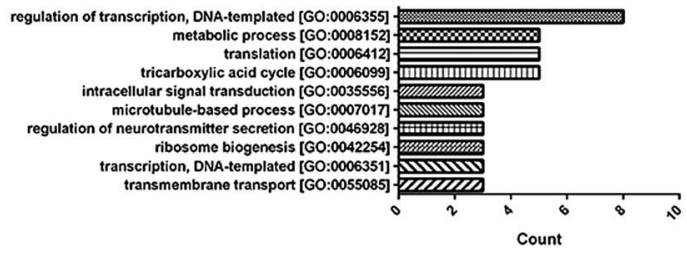

Figure 1. Top 10 enriched gene ontology terms among potential excretory-secretory protein (ESP) transcripts from advanced third-stage larvae of Gnathostoma spinigerum (aL3Gs). Classical (left) and non-classical ESPs (right) were categorized into three gene ontology classifications: molecular functions (upper), cellular components (middle), and biological processes (lower). Gene ontology functions are shown on the left $Y$-axis. The number of transcripts is shown on the right $Y$-axis.

(7.8\%), and metal ion binding $(6.5 \%)$; the predominant terms listed for "Cellular component" were integral component of membrane $(54.6 \%)$, nucleus $(10.7 \%)$, and intracellular $(5.5 \%)$, while those for "Biological process" were transcription $(5.0 \%)$, regulation of transcription (4.2\%), and metabolic process $(4.1 \%)$ (Supplementary Fig. S7). After annotation of the transcripts with three different databases, all 37,099 protein-coding contigs could be assigned some possible functions and could have their excretory-secretory potential predicted. Detailed information about the assembled contig annotation is shown in Supplementary Table S1.

\section{Potential excretory-secretory proteins and functional annotation}

Infective-stage aL3Gs cause cutaneous gnathostomiasis, as well as severe visceral gnathostomiasis via infection of the central nervous system and eyes in humans [26]. ESPs released from larvae include several molecules that play important roles in the parasite itself and also host-parasite interaction including nutrient uptake, tissue invasion, migration, inflammation, and immunomodulation [62]. Therefore, the identification and characterization of these proteins could clarify parasite homeostasis and the host-parasite interaction, which facilitate the development of control strategies against gnathostomiasis, including drugs and vaccines. Furthermore, ESPs can be used for the immunodiagnosis of parasitic infection and for patient monitoring after anthelminthic treatment, as previously demonstrated in several studies of parasitic helminth infection [14, 19, 33, 57].

From among 35,850 NCBI CDD-annotated proteins, 171 proteins contained a signal peptide and were categorized as potential classical ESPs, whereas 292 proteins that contained a secretory signal but lacked a signal peptide were categorized as potential non-classical ESPs. Therefore, 463 predicted proteins were identified as potential ESPs of aL3Gs.

The 171 potential classical ESPs were classified into protein functional groups according to GO classification. The largest number of proteins were classified as "Molecular function" $(n=106)$, followed by "Cellular component" $(n=77)$ and "Biological process" $(n=64)$, respectively. ATP binding $(n=12)$ was the most predominant term in "Molecular function," while integral component of membrane $(n=26)$ was the most predominant term in "Cellular component." Metabolic process $(n=6)$ was the top GO term identified in "Biological process." Among the 292 non-classical ESPs, "Molecular function" ( $n=152)$ was most abundant, followed by "Cellular component" $(n=122)$ and "Biological process" $(n=92)$. ATP binding $(n=10)$ and DNA binding $(n=10)$ were the most predominant terms in "Molecular function." For "Cellular component" and "Biological process," the most predominant terms were integral component of membrane $(n=51)$ and regulation of transcription, DNA-templated $(n=8)$, respectively (Fig. 1).

The top 50 most significant potential functional proteins using BLAST with an $E$-value cut-off $<10^{-5}$ among both the potential classical and non-classical ESPs are listed in 
Table 2. Top 50 significant potential functional proteins in classical excretory-secretory proteins from the advanced third-stage larvae of Gnathostoma spinigerum (aL3Gs) transcriptome.

\begin{tabular}{|c|c|c|c|}
\hline No. & Protein names & Transcript ID & $E$-value \\
\hline 1 & Neurexin-4 & comp18192_seq0 & 0 \\
\hline 2 & Uncharacterized protein & comp6231_seq3 & 0 \\
\hline 3 & Uncharacterized protein & comp6345_seq2 & 0 \\
\hline 4 & Pecanex-like protein 1 & comp6414_seq3 & 0 \\
\hline 5 & 5-oxoprolinase & comp7397_seq4 & 0 \\
\hline 6 & Transcription initiation factor tfiid subunit 2 & comp8460_seq2 & 0 \\
\hline 7 & Alpha-1,2-Mannosidase (EC 3.2.1.-) & comp960_seq3 & 0 \\
\hline 8 & Elongation factor $\mathrm{G}$ & comp3740_seq0 & $1.80 \mathrm{E}-274$ \\
\hline 9 & Putative diacylglycerol kinase K06A1.6 (DAG kinase) & comp2814_seq4 & $5.20 \mathrm{E}-264$ \\
\hline 10 & Uncharacterized protein & comp8944_seq1 & $9.10 \mathrm{E}-252$ \\
\hline 11 & Arylsulfatase & comp1959_seq0 & $7.70 \mathrm{E}-250$ \\
\hline 12 & Arylsulfatase & comp1959_seq3 & $1.10 \mathrm{E}-249$ \\
\hline 13 & $26 \mathrm{~S}$ protease regulatory subunit 7 (Fragment) & comp1510_seq0 & $9.80 \mathrm{E}-244$ \\
\hline 14 & $26 \mathrm{~S}$ protease regulatory subunit 7 (Fragment) & comp1510_seq1 & $9.80 \mathrm{E}-244$ \\
\hline 15 & Uncharacterized protein & comp5002_seq2 & $1.00 \mathrm{E}-217$ \\
\hline 16 & Carboxypeptidase A2 & comp6316_seq2 & $8.20 \mathrm{E}-214$ \\
\hline 17 & Uncharacterized protein & comp6105_seq2 & 8.60E-209 \\
\hline 18 & Carboxypeptidase A2 & comp6316_seq0 & $2.00 \mathrm{E}-206$ \\
\hline 19 & Elongation factor $\mathrm{G}$ & comp3740_seq2 & $4.70 \mathrm{E}-187$ \\
\hline 20 & Coiled-coil and c2 domain-containing protein 1-like protein & comp5185_seq6 & $3.00 \mathrm{E}-182$ \\
\hline 21 & Coiled-coil and c2 domain-containing protein 1 -like protein & comp5185_seq3 & $3.10 \mathrm{E}-182$ \\
\hline 22 & Sodium-dependent serotonin transporter & comp7361_seq6 & $3.50 \mathrm{E}-173$ \\
\hline 23 & Cathepsin B-like cysteine proteinase 6 & comp736_seq0 & $2.20 \mathrm{E}-164$ \\
\hline 24 & Cathepsin B-like cysteine proteinase 6 & comp736_seq1 & $2.20 \mathrm{E}-164$ \\
\hline 25 & Cathepsin B-like cysteine proteinase 6 & comp736_seq2 & $2.70 \mathrm{E}-164$ \\
\hline 26 & Cathepsin B-like cysteine proteinase 6 & comp736_seq4 & $3.30 \mathrm{E}-164$ \\
\hline 27 & Cathepsin B-like cysteine proteinase 6 & comp736_seq3 & $3.40 \mathrm{E}-164$ \\
\hline 28 & Cathepsin B-like cysteine proteinase 6 & comp736_seq5 & $3.40 \mathrm{E}-164$ \\
\hline 29 & Cre-eff-1 protein & comp16964_seq1 & $1.70 \mathrm{E}-163$ \\
\hline 30 & Raf serine/threonine-protein kinase & comp3619_seq2 & $5.50 \mathrm{E}-160$ \\
\hline 31 & Cre-eff-1 protein & comp16964_seq0 & $3.60 \mathrm{E}-158$ \\
\hline 32 & P-GlycoProtein related & comp22636_seq0 & $5.00 \mathrm{E}-157$ \\
\hline 33 & P-GlycoProtein related & comp22636_seq1 & $5.00 \mathrm{E}-157$ \\
\hline 34 & Ribonucleoside-diphosphate reductase small chain & comp3298_seq1 & $2.60 \mathrm{E}-156$ \\
\hline 35 & Ribonucleoside-diphosphate reductase small chain & comp3298_seq2 & $2.60 \mathrm{E}-156$ \\
\hline 36 & Raf serine/threonine-protein kinase & comp3619_seq0 & $3.10 \mathrm{E}-146$ \\
\hline 37 & Prolyl 4-hydroxylase subunit alpha-1 & comp20829_seq1 & $2.00 \mathrm{E}-145$ \\
\hline 38 & Beta-1,3-glucosyltransferase & comp9587_seq1 & $2.40 \mathrm{E}-136$ \\
\hline 39 & Uncharacterized protein & comp11306_seq1 & $1.10 \mathrm{E}-129$ \\
\hline 40 & Peptidase M14 & comp2857_seq0 & $3.90 \mathrm{E}-129$ \\
\hline 41 & Uncharacterized protein & comp1752_seq0 & $1.40 \mathrm{E}-123$ \\
\hline 42 & Uncharacterized protein & comp1752_seq1 & $1.40 \mathrm{E}-123$ \\
\hline 43 & Casein kinase II subunit beta (CK II beta) & comp663_seq4 & $5.10 \mathrm{E}-119$ \\
\hline 44 & Uncharacterized protein & comp6326_seq4 & $4.40 \mathrm{E}-111$ \\
\hline 45 & Putative RNA 3'-terminal phosphate cyclase-like protein & comp2261_seq3 & $2.10 \mathrm{E}-109$ \\
\hline 46 & Flap endonuclease 1 (FEN-1) & comp5588_seq0 & $5.00 \mathrm{E}-103$ \\
\hline 47 & Serine/threonine protein phosphatase & comp4127_seg0 & $3.30 \mathrm{E}-98$ \\
\hline 48 & Phosphatidylethanolamine-binding protein & comp456_seq1 & $9.30 \mathrm{E}-87$ \\
\hline 49 & Uncharacterized protein & comp1050_seq1 & $1.40 \mathrm{E}-85$ \\
\hline 50 & Uncharacterized protein & comp9949_seq0 & 4.10E-84 \\
\hline
\end{tabular}

Tables 2 and 3, respectively. Information about all the recruited potential classical and non-classical ESPs is listed in Supplementary Table S4, respectively. The top 50 significant potential classical ESPs included transcripts associated with neuronal proteins (neurexin-4 and sodium-dependent serotonin transporter), cell signaling (diacylglycerol kinase, coiled-coil and c2 domain-containing protein 1-like protein,
Raf serine/threonine protein kinase, serine/threonine protein phosphatase, casein kinase II, P-glycoprotein, and phosphatidylethanolamine-binding protein) and proteases (cathepsin B, carboxypeptidase A2, and peptidase M14). Moreover, several transcripts encoding metabolic proteins (5-oxoprolinase, arylsulfatase, and ribonucleoside-diphosphate reductase) and post-translation-related proteins (alpha-1,2-mannosidase, 
Table 3. Top 50 significant potential functional proteins in non-classical excretory-secretory proteins from the advanced third-stage larvae of Gnathostoma spinigerum (aL3Gs) transcriptome.

\begin{tabular}{|c|c|c|c|}
\hline No. & Protein names & Transcript ID & $E$-value \\
\hline 1 & Integrin alpha pat-2 & comp1772_seq0 & 0 \\
\hline 2 & Glycogen [starch] synthase & comp3052_seq0 & 0 \\
\hline 3 & JNK-interacting protein, variant & comp3890_seq1 & 0 \\
\hline 4 & Uncharacterized protein & comp3952_seq13 & 0 \\
\hline 5 & Uncharacterized protein & comp3952_seq8 & 0 \\
\hline 6 & Cytoplasmic FMR1-interacting-like protein & comp5249_seq0 & 0 \\
\hline 7 & ATP-dependent RNA helicase DDX46 & comp5447_seq2 & 0 \\
\hline 8 & Spectrin beta chain & comp899_seq1 & 0 \\
\hline 9 & Arginyl-tRNA synthetase (Fragment) & comp3718_seq0 & $2.80 \mathrm{E}-289$ \\
\hline 10 & Eukaryotic translation initiation factor 3 subunit D (eIF3d) & comp1927_seq1 & $4.80 \mathrm{E}-270$ \\
\hline 11 & Uncharacterized protein & comp6944_seq0 & $3.30 \mathrm{E}-263$ \\
\hline 12 & Putative aconitate hydratase 1 & comp7480_seq1 & $1.00 \mathrm{E}-257$ \\
\hline 13 & Phosphoinositide phospholipase $\mathrm{C}$ & comp6826_seq0 & $1.10 \mathrm{E}-245$ \\
\hline 14 & BMA-SMG-6, isoform d & comp8286_seq0 & $5.90 \mathrm{E}-245$ \\
\hline 15 & Putative aconitate hydratase 1 & comp7480_seq4 & $3.10 \mathrm{E}-244$ \\
\hline 16 & Uncharacterized protein & comp7268_seq2 & $9.60 \mathrm{E}-242$ \\
\hline 17 & Phosphatidylinositide phosphatase SAC2 & comp1296_seq9 & $1.20 \mathrm{E}-239$ \\
\hline 18 & Tubulin beta chain & comp10855_seq0 & $1.00 \mathrm{E}-234$ \\
\hline 19 & Tubulin beta chain & comp10855_seq1 & $1.00 \mathrm{E}-234$ \\
\hline 20 & UPF0577 protein-like protein & comp27596_seq0 & $2.70 \mathrm{E}-225$ \\
\hline 21 & Tyrosine-protein phosphatase non-receptor type II & comp5184_seq2 & $2.20 \mathrm{E}-215$ \\
\hline 22 & Uncharacterized protein & comp4857_seq0 & $1.70 \mathrm{E}-214$ \\
\hline 23 & Uncharacterized protein & comp4857_seq1 & $2.80 \mathrm{E}-212$ \\
\hline 24 & Uncharacterized protein & comp5818_seq0 & $1.10 \mathrm{E}-201$ \\
\hline 25 & Telomerase-binding protein EST1A & comp8286_seq1 & $6.60 \mathrm{E}-182$ \\
\hline 26 & Uncharacterized protein & comp7823_seq1 & $6.00 \mathrm{E}-173$ \\
\hline 27 & Uncharacterized protein & comp9114_seq3 & $3.60 \mathrm{E}-169$ \\
\hline 28 & Histone acetyltransferase & comp2414_seq3 & $2.70 \mathrm{E}-166$ \\
\hline 29 & Histone acetyltransferase & comp2414_seq4 & $2.70 \mathrm{E}-166$ \\
\hline 30 & Synaptonemal complex protein SC65 & comp7780_seq0 & $3.30 \mathrm{E}-164$ \\
\hline 31 & Uncharacterized protein & comp2379_seq4 & $9.20 \mathrm{E}-164$ \\
\hline 32 & Uncharacterized protein & comp856_seq0 & $2.80 \mathrm{E}-162$ \\
\hline 33 & Uncharacterized protein & comp3356_seq0 & $3.70 \mathrm{E}-158$ \\
\hline 34 & Uncharacterized protein & comp3172_seq3 & $3.90 \mathrm{E}-157$ \\
\hline 35 & Uncharacterized protein & comp2499_seq0 & $2.70 \mathrm{E}-154$ \\
\hline 36 & RNA polymerase II elongation factor ELL & comp3620_seq1 & $2.40 \mathrm{E}-152$ \\
\hline 37 & Uncharacterized protein & comp7268_seq3 & $3.80 \mathrm{E}-147$ \\
\hline 38 & Putative RNA 3'-terminal phosphate cyclase-like protein & comp2261_seq1 & $7.70 \mathrm{E}-146$ \\
\hline 39 & Uncharacterized protein & comp856_seq2 & $8.90 \mathrm{E}-146$ \\
\hline 40 & Stromal interaction molecule & comp2776_seq0 & $2.70 \mathrm{E}-144$ \\
\hline 41 & Galectin & comp442_seq0 & $1.30 \mathrm{E}-142$ \\
\hline 42 & Galectin & comp442_seq1 & $1.30 \mathrm{E}-142$ \\
\hline 43 & Putative sodium potassium-transporting ATPase subunit beta-3 & comp4663_seq0 & $2.30 \mathrm{E}-141$ \\
\hline 44 & Nuclear hormone receptor E75 & comp5290_seg0 & $6.80 \mathrm{E}-138$ \\
\hline 45 & Nuclear hormone receptor E75 & comp5290_seq1 & $6.80 \mathrm{E}-138$ \\
\hline 46 & Ancient ubiquitous protein 1 -like protein & comp1622_seq3 & $3.90 \mathrm{E}-136$ \\
\hline 47 & Uncharacterized protein & comp5136_seq2 & $4.10 \mathrm{E}-134$ \\
\hline 48 & Ectonucleotide pyrophosphatase/phosphodiesterase family member 4 & comp328_seq2 & $1.20 \mathrm{E}-131$ \\
\hline 49 & Uncharacterized protein & comp510_seq2 & $1.40 \mathrm{E}-130$ \\
\hline 50 & ATP-dependent RNA helicase DDX56 & comp4028_seq4 & $6.00 \mathrm{E}-127$ \\
\hline
\end{tabular}

beta-1,3-glucosyltransferase, and $26 \mathrm{~S}$ protease regulator) were also listed as top 50 significant potential classical ESPs. The top 50 potential non-classical ESPs included transcripts encoding proteins associated with adhesion (integrin alpha pat-2) and cytoskeleton (spectrin beta chain and tubulin beta chain). This category also included groups of transcripts related to metabolism (aconitate hydrolase, phosphoinositide phospholipase, and ectonucleotide pyrophosphatase/phosphodiesterase family member 4), biomolecule synthesis (glycogen synthase and arginyl-tRNA synthetase), and ion transportation (stromal interaction molecule and putative sodium potassium-transporting ATPase subunit beta-3). 


\section{Identification of aL3Gs secretory proteins}

ESPs biochemically isolated from aL3Gs were electrically separated by $12 \%$ SDS-PAGE, and the proteins were identified using mass spectrometry (MS). The ESPs were distributed at the molecular size range from 10 to $250 \mathrm{kDa}$. The gel was subsequently cut into 16 equal-sized rectangles prior to MS analysis (Fig. 2). After MS analysis, 29 proteins were identified and allocated into nine functional groups (Table 4). A metalloendopeptidase and serine carboxypeptidase belonging to the protease group were identified as ESPs of aL3Gs. Moreover, the serine protease inhibitor, serpin, was identified as a protease inhibitor group member. Interestingly, several proteins involved in signaling transduction, transcriptional regulation, transportation, and programmed cell death were identified among the ES products of aL3Gs. However, the functions of 19 hypothetical proteins remained unknown and will require further investigation.

\section{Determination of immunodiagnostic target using 2-DE and immunomics}

Western blot analysis for the detection of IgG antibodies against the 24-kDa CWA has been used as a gold standard method for diagnosing $G$. spinigerum infection. However, the identification of additional targets could improve the reliability of gnathostomiasis immunodiagnosis. Accordingly, we conducted a 2-DE/immunomic analysis to determine potential targets for immunodiagnosis. A comparison of the reactive patterns of pooled human serum samples from patients with selected helminthic infections was performed, and the result demonstrated that seven spots were specifically recognized by pooled sera from patients with G. spinigerum (Fig. 3). The spots were collected and subjected to MS to assess the protein types; Table 5 includes a list of these proteins. Several spots (spots 4-7) predominantly recognized by $G$. spinigerumhuman pooled sera yielded proteins with a molecular weight of $48 \mathrm{kDa}$ but different $\mathrm{pI}$ values and were identified as serine protease inhibitors (serpins; GsSerp). The nucleotide and deduced amino acid sequences of GsSerp (comp9_seq4) were obtained from the aL3Gs transcriptomic database and used for further bioinformatics analysis.

\section{Serine protease inhibitor of $G$. spinigerum}

The nucleotide and amino acid sequences of the identified GsSerp (comp9_seq4) were submitted to the NCBI database for accession number assignment and renamed to GsSerp1. Other GsSerp isoforms were also identified from the transcriptomic database and subjected to accession number assignment by the NCBI database. Eleven different isoforms (GsSerp111) were obtained; their accession numbers are provided in Table 6. The amino acid homology and relationships among GsSerp isoforms were analyzed through a multiple alignment conducted using MUSCLE software, after which a phylogenetic tree was constructed based on a maximum likelihood analysis with 1000 bootstrap replications using the MEGA $\mathrm{X}$ program [34]. Our results demonstrated that GsSerp1 was most closely related to GsSerp9 but distinctly separated from the

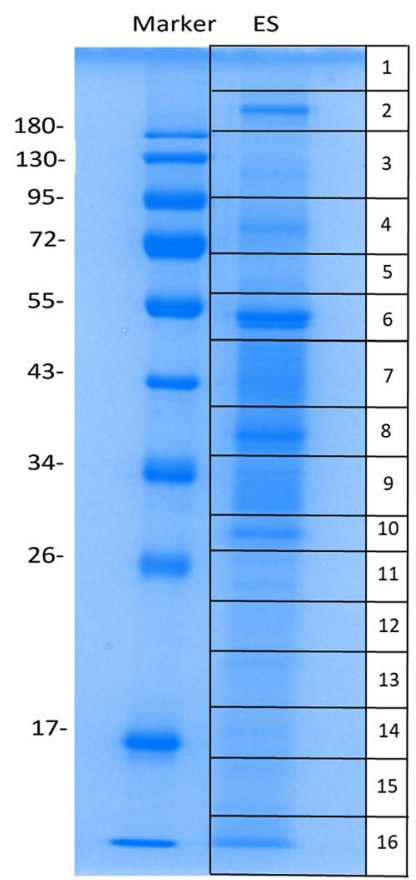

Figure 2. Excretory-secretory proteins from advanced third-stage larvae of Gnathostoma spinigerum (aL3Gs). These proteins were examined after separation by one-dimensional gel electrophoresis and excision of whole lanes into 16 rectangular pieces.

other isoforms (Fig. 4). To evaluate the diagnostic potential of GsSerp1, we included it in a homology comparison with serpins of other parasitic helminths, protozoa, and humans (Table 6) using a multiple alignment via MUSCLE software (https://www.ebi.ac.uk/Tools/msa/muscle/) and the MEGA X program [34]. A phylogenetic tree was then constructed using the abovementioned parameters, and the tree demonstrated close relationships of GsSerp1 with both hookworm (A. caninum, A. ceylanicum and N. americanus) and Ascarididae (A. suum and $T$. canis) serpins (Figure 5 ). The pairwise sequence identity and similarity were calculated from a multiple alignment of GsSerp1 and its orthologs via the Sequence Identity and Similarity program (http://imed.med.ucm.es/Tools/sias.html) and were subsequently visualized as a heatmap table using heatmapper software (http://heatmapper.ca). The homology heatmap suggested that GsSerp1 shared low identity (less than $30 \%$ ) with all orthologs, even hookworm and Ascarididae serpins (Fig. 6).

\section{Discussion}

In Southeast Asia, G. spinigerum is a major causative agent of gnathostomiasis, a life-threatening parasitic disease in both humans and animals. However, the lack of available genome, transcriptome, and proteome databases remains a hindrance to the development of effective prevention and control strategies, including drugs, vaccines, and diagnostic methods. In this study, a pioneer transcriptomic database of aL3Gs was constructed in a $2 \times 150$ bp paired-end (PE) configuration with incorporated bioinformatics analysis using the Illumina HiSeq platform. A total of $61,602,864$ paired reads were obtained 
Table 4. Proteins identified from excretory-secretory products of the advanced third-stage larvae of Gnathostoma spinigerum (aL3Gs).

\begin{tabular}{|c|c|c|c|c|c|}
\hline$\overline{\text { No. }}$ & Protein & Transcripts & Score & $\begin{array}{l}\text { Molecular } \\
\text { weight }\end{array}$ & $\%$ Coverage \\
\hline \multicolumn{6}{|c|}{ Protease } \\
\hline 1 & Carboxypeptidase (EC 3.4.16.-) & comp3365_seq0 & 155 & 59560 & 7.1 \\
\hline 2 & Carboxypeptidase (EC 3.4.16.-) & comp610_seq0 & 62 & 124018 & 2.2 \\
\hline 3 & Metalloendopeptidase (EC 3.4.24.-) & comp37_seq0 & 250 & 93544 & 8.4 \\
\hline 4 & Metalloendopeptidase (EC 3.4.24.-) & comp37_seq2 & 147 & 101515 & 4 \\
\hline \multicolumn{6}{|c|}{ Unknown } \\
\hline 5 & Uncharacterized protein & comp455_seq9 & 194 & 158997 & 3.9 \\
\hline 6 & Uncharacterized protein & comp455_seq10 & 184 & 196865 & 2.6 \\
\hline 7 & Uncharacterized protein & comp455_seq11 & 183 & 158453 & 3.2 \\
\hline 8 & Uncharacterized protein & comp4307_seq0 & 133 & 42986 & 7.7 \\
\hline 9 & Uncharacterized protein & comp871_seq11 & 96 & 454446 & 0.7 \\
\hline 10 & Uncharacterized protein & comp1222_seq0 & 56 & 72917 & 2.9 \\
\hline 11 & Putative uncharacterized protein & comp109_seq0 & 87 & 48242 & 5 \\
\hline 12 & Uncharacterized protein & comp2379_seq0 & 50 & 318310 & 1.3 \\
\hline 13 & Uncharacterized protein & comp9_seq4 & 802 & 130306 & 16 \\
\hline 14 & Uncharacterized protein & comp72_seq1 & 124 & 325233 & 2.4 \\
\hline 15 & Protein CBG11500 & comp10_seq4 & 62 & 292750 & 0.9 \\
\hline 16 & Uncharacterized protein & comp4152_seq1 & 47 & 199737 & 0.9 \\
\hline 17 & Uncharacterized protein & comp22_seq2 & 178 & 411932 & 1.7 \\
\hline 18 & Uncharacterized protein & comp0_seq5 & 55 & 456002 & 0.9 \\
\hline 19 & Uncharacterized protein & comp23_seq0 & 341 & 19720 & 42.1 \\
\hline \multicolumn{6}{|c|}{ Cytoskeletal protein } \\
\hline 19 & Talin-1 & comp783_seq0 & 47 & 413351 & 1.1 \\
\hline 20 & Apx/Shroom domain ASD1 & comp171_seq0 & 61 & 49558 & 4.8 \\
\hline \multicolumn{6}{|c|}{ Protease inhibitor } \\
\hline 21 & Serpin-like protein & comp86_seq0 & 210 & 68930 & 4.7 \\
\hline 22 & Serpin-like protein & comp86_seq1 & 205 & 68971 & 10.6 \\
\hline 23 & Serpin-like protein (Fragment) & comp86_seq2 & 63 & 44673 & 5.5 \\
\hline \multicolumn{6}{|c|}{ Lipid metabolism } \\
\hline 24 & MACS_like_1 & comp115_seq0 & 57 & 64895 & 1.9 \\
\hline \multicolumn{6}{|c|}{$\begin{array}{l}\text { Carbohydrate transport } \\
\text { and metabolism }\end{array}$} \\
\hline 25 & $\begin{array}{l}\text { Polypeptide } \mathrm{N} \text {-acetylgalactosaminyltransferase } \\
\text { (EC 2.4.1.-) }\end{array}$ & comp9_seq1 & 108 & 320030 & 1.4 \\
\hline 26 & $\begin{array}{l}\text { Polypeptide } \mathrm{N} \text {-acetylgalactosaminyltransferase } \\
\text { (EC 2.4.1.-) }\end{array}$ & comp9_seq2 & 129 & 308383 & 2.2 \\
\hline \multicolumn{6}{|c|}{ Transcriptional regulation } \\
\hline 27 & Tyrosyl-DNA phosphodiesterase & comp140_seq1 & 50 & 87509 & 1.8 \\
\hline \multicolumn{6}{|c|}{ Signaling pathway } \\
\hline 28 & $\begin{array}{l}\text { PAS domain-containing serine/threonine-protein } \\
\text { kinase }\end{array}$ & comp45_seq2 & 72 & 162264 & 3.5 \\
\hline \multicolumn{6}{|c|}{ Catalytic activity } \\
\hline 29 & 3-isopropylmalate dehydratase large subunit & comp13021_seq0 & 49 & 35761 & 6.7 \\
\hline
\end{tabular}

and subjected to a quality assessment with a quality score (value of Q30) greater than $80 \%$. In addition, $89.6 \%$ of raw reads could be aligned to assembled sequences, indicating the presence of high-quality sequences and, consequently, an effective assembly and downstream data analysis was performed. The resulting contigs were arranged in groups, which enabled us to obtain transcript variants. We identified 86,312 splice variant groups (mean $=2.18$ splice variants per group), suggesting a broad transcript diversity in this sequence database.

A G. spinigerum genome is not currently available [38]; therefore, a de novo assembly was obtained in this study to generate assembled sequences. High-quality sequences were subjected to assembly using the Bridger [11] assembler, which was selected because it provided the best accuracy while maximizing the utility of the PE reads. Bridger also enables the most complete reconstruction of transcripts, compared with other assemblers [50].

Gene ontology annotation demonstrated that transcription processes were highly represented within the biological process category of aL3Gs, and the result indicated the expression of several genes responsible for transcription factors and transcription regulation, including the transcription elongation factor 1 homolog, transcription elongation factor SPT5, RuvB-like 


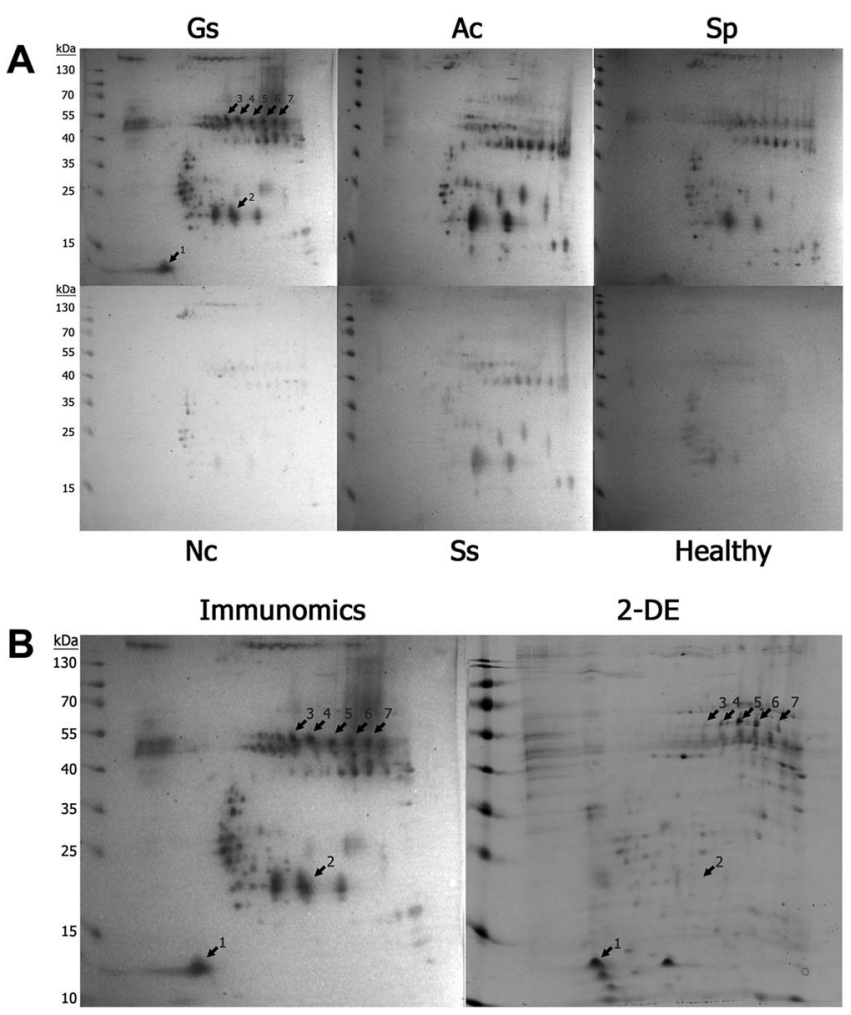

Figure 3. Two-dimensional (2D)-immunomics of advanced thirdstage larvae of Gnathostoma spinigerum (aL3Gs) reacted with human sera. Two-dimensional (2D)-immunomics of advanced thirdstage larvae of Gnathostoma spinigerum (aL3Gs) reacted with human sera from patients infected with $G$. spinigerum and other related helminths (A) Gs, G. spinigerum-infected human sera; Ac, Angiostrongylus cantonensis-infected sera; Sp, sparganosis sera; Nc, neurocysticercosis sera; Ss, Strongyloides stercoralis-infected sera; Healthy, healthy sera. After comparing the patterns of reactivity among the serum samples, seven spots were found to react specifically with $G$. spinigerum-infected sera. The spot patterns were compared with the 2D-gel, from which the proteins were excised for identification using mass spectrometry (B). Immunomics, 2D-immunomics; 2DE, 2D-gel electrophoresis. Arrows indicate the spots that reacted specifically with $G$. spinigerum-infected human sera.

helicase, general transcription factor IIH subunit 1, histone deacetylase, histone acetyltransferase, repressor of RNA polymerase III transcription MAF1, Zinc finger homeobox protein 3, and DNA-directed RNA polymerase subunit. The expressions of these genes suggest a high level of transcriptional activity during this infective stage. As aL3Gs is a developmental stage during which the organism transitions between stages, changes in the expression of genes with predicted functions in many biological processes are needed to enable the physical and physiological changes associated with growth and development [37].

Integral membrane proteins, especially transmembrane proteins, were the most frequently identified cellular component among aL3Gs, and included transporter proteins (ABC transporter ATP-binding protein, amino acid transporter, metal transporter cnnm4, organic cation transporter protein, sodium- and chloride-dependent glycine transporter 2, and zinc transporter
1) and ion channel proteins (ligand-gated ion channel, organic cation transporter protein, solute carrier organic anion transporter family member, acid-sensing ion channel 1, TWiK family of potassium channels protein 7 , and voltage-dependent calcium channel type A subunit alpha-1). Several studies have reported a response of transporter and ion channel proteins to translocate a substrate across cell membranes. The high levels of expression of various transporter proteins indicate that various nutrients are required for growth and development in this stage $[18,68]$. However, this phenomenon remains to be clarified in other developmental stages.

ATP binding activity, especially kinase activity, was the most active function in aL3Gs; specifically, this activity involved the mitogen-activated protein (MAP) kinase family, which includes dual-specificity mitogen-activated protein kinase 4, dual-specificity mitogen-activated protein kinase 6 , dual-specificity mitogen-activated protein kinase 7 , and dualspecificity mitogen-activated protein kinase mek-2. In mammals, MAP kinases are the major components of pathways that control embryogenesis, cell differentiation, cell proliferation, and cell death [48]. In parasites, however, little is known about protein kinases, although they might play key roles in proliferation, differentiation, and invasion [52]. Several studies conducted in Plasmodia, Leishmania, and Toxoplasma found that MAP kinase signaling events play a role in parasitic immune evasion and thus promote survival in the host $[8,25,30,56]$. The extrapolation of these findings to $G$. spinigerum implies that MAP kinase signaling pathways are involved in several indispensable activities.

Prediction of potential ESPs of aL3Gs was used as a guide to verify proteins with a potential to excrete inside the parasite or secrete outside to interact with the host environment. However, recently available prediction programs could not differentiate between excretory- and secretory proteins, which need to be intensively proven by experimental evidence, and this will be a priority in future studies. In the "Molecular function" category, ATP binding was the top GO term identified for both potential classical and non-classical ESPs, which included protein kinases (nucleoside diphosphate kinase, Raf serine/threonine protein kinase, pantothenate kinase 1, and 3-phosphoinositide-dependent protein kinase 1) and replication, transcription, and translation (ATP-dependent RNA helicase DDX56, regulator of nonsense transcripts 1 , and 26S protease regulatory subunit 7 ). These transcripts may directly affect growth regulation, development, and survival of the parasite, as mentioned above. Moreover, the secreted forms of these proteins may act as an extracellular signal to regulate the host at a molecular level and thus provide suitable niches for parasite growth and development or the evasion of host defense mechanisms. ESPs of the liver fluke Opisthorchis viverrini were shown to stimulate fibroblast cell proliferation by upregulating genes that encoding proteins associated with metabolism, signal transduction, replication, transcription and translation, matrix and structural proteins, and cell cycle [60, 61]. ESPs derived from Heligmosomoides polygyrus could stimulate host regulatory responses by inducing Foxp $3^{+}$Treg cells and the TGF- $\beta$ signaling pathway [24]. Regarding G. spinigerum, ESPs of aL3Gs impaired the human monocyte phagocytosis by downregulating Fc $\gamma$ RI expression [6]. 
Table 5. Immunogens identified from excretory-secretory products of advanced third-stage larvae of Gnathostoma spinigerum (aL3Gs).

\begin{tabular}{|c|c|c|c|c|c|c|c|}
\hline $\begin{array}{l}\text { Spot } \\
\text { no. }\end{array}$ & $\begin{array}{l}\text { Protein } \\
\text { no. }\end{array}$ & Transcripts & Protein & Score & $\begin{array}{l}\text { Molecular } \\
\text { weight }\end{array}$ & $\begin{array}{c}\% \\
\text { coverage }\end{array}$ & Sequence \\
\hline 1 & 1 & comp5644_seq4 & Serine_rich_NEDD9 & 94 & 74822 & 2.7 & $\begin{array}{l}\text { CTVSPLR } \\
\text { YFLLSQLFICTK }\end{array}$ \\
\hline 2 & 1 & comp7822_seq0 & Catalase heme-binding enzyme & 96 & 101056 & 2.1 & $\begin{array}{l}\text { LTDLLDFHS } \\
\text { ECNLQLSTSK }\end{array}$ \\
\hline \multirow[t]{3}{*}{3} & $\begin{array}{l}1 \\
2\end{array}$ & $\begin{array}{l}\text { comp65414_seq0 } \\
\text { comp6066_seq0 }\end{array}$ & $\begin{array}{l}\text { Uncharacterized protein } \\
\text { Pyrroline-5-carboxylate } \\
\text { reductase }\end{array}$ & $\begin{array}{l}76 \\
72\end{array}$ & $\begin{array}{c}13604 \\
104867\end{array}$ & $\begin{array}{l}5.6 \\
0.8\end{array}$ & $\begin{array}{l}\text { LAVSDMR } \\
\text { RATVLSPR }\end{array}$ \\
\hline & 4 & comp6937_seq0 & $\begin{array}{l}\text { Phospho-2-dehydro- } \\
\text { 3-deoxyheptonate aldolase }\end{array}$ & 96 & 113706 & 1.7 & LLLASLNP \\
\hline & 5 & comp7822_seq0 & Catalase heme-binding enzyme & 90 & 102122 & 2.1 & $\begin{array}{l}\text { SLFIGGTVA } \\
\text { LTDLLDFHS } \\
\text { ECNLQLSTSK }\end{array}$ \\
\hline 4 & 1 & comp9_seq4 & Serpin & 153 & 130306 & 4.3 & $\begin{array}{l}\text { SSPISAIFTSFK } \\
\text { TATGGFVKGTVEER } \\
\text { QVISPVAESLALGAVYEGSQDETR }\end{array}$ \\
\hline \multirow[t]{3}{*}{5} & 1 & comp9_seq4 & Serpin & 930 & 130306 & 14.3 & $\begin{array}{l}\text { WKNPLTK } \\
\text { MFHAETR } \\
\text { YNFNKPK } \\
\text { GSGEYLYK } \\
\text { TNYEAVEK } \\
\text { QIGIAMFGTK } \\
\text { IAATETEEWVK } \\
\text { SSPISAIFTSFK } \\
\text { TATGGFVKGTVEER } \\
\text { FSYEQQFLTSLK } \\
\text { ESGEFGGKQVSFLK } \\
\text { FVANRPFFFALVR } \\
\text { RFSYEQQFLTSLK } \\
\text { IAATETEEWVKTATGGFVK } \\
\text { GESYGELEKEINGETIILK } \\
\text { QVISPVAESLALGAVYEGSQDETR } \\
\text { QVISPVAESLALGAVYEGSQDETRK }\end{array}$ \\
\hline & 2 & comp23_seq0 & Uncharacterized protein & 435 & 19720 & 36.5 & $\begin{array}{l}\text { QIGIAMFGTK } \\
\text { FSYEQQFLTSLK } \\
\text { RFSYEQQFLTSLK } \\
\text { LADFGLSLFQLSSQPGK } \\
\text { QVISPVAESLALGAVYEGSQDETR } \\
\text { QVISPVAESLALGAVYEGSQDETRK }\end{array}$ \\
\hline & 3 & comp7822_seq0 & Catalase heme-binding enzyme & 98 & 102122 & 2.1 & $\begin{array}{l}\text { LTDLLDFHS } \\
\text { ECNLQLSTSK }\end{array}$ \\
\hline 6 & 1 & comp9_seq4 & Serpin & 559 & 130306 & 9.7 & $\begin{array}{l}\text { WKNPLTK } \\
\text { YNFNKPK } \\
\text { SSPISAIFTSFK } \\
\text { TATGGFVKGTVEER } \\
\text { FSYEQQFLTSLK } \\
\text { FVANRPFFFALVR } \\
\text { QVISPVAESLALGAVYEGSQDETR } \\
\text { QVISPVAESLALGAVYEGSQDETRK } \\
\text { NSTAPHDSTVMKVMAENVLRPHVR }\end{array}$ \\
\hline & 2 & comp23_seq0 & Uncharacterized protein & 256 & 19697 & 30.3 & $\begin{array}{l}\text { FSYEQQFLTSLK } \\
\text { LADFGLSLFQLSSQPGK } \\
\text { QVISPVAESLALGAVYEGSQDETR } \\
\text { QVISPVAESLALGAVYEGSQDETRK }\end{array}$ \\
\hline \multirow[t]{3}{*}{7} & 1 & comp9_seq4 & Serpin & 176 & 130306 & 4.3 & $\begin{array}{l}\text { SSPISAIFTSFK } \\
\text { TATGGFVKGTVEER } \\
\text { QVISPVAESLALGAVYEGSQDETR }\end{array}$ \\
\hline & 2 & comp7822_seq0 & Catalase heme-binding enzyme & 118 & 101056 & 2.2 & $\begin{array}{l}\text { QTCSISIR } \\
\text { LTDLLDFHS } \\
\text { ECNLQLSTSK }\end{array}$ \\
\hline & 3 & comp22636_seq0 & AJAP1/PANP C-terminus & 97 & 53020 & 5.3 & $\begin{array}{l}\text { ATTSVMAVSIPR } \\
\text { KLTVVSIECIMIR }\end{array}$ \\
\hline
\end{tabular}


Table 6. Amino acid sequences and the corresponding accession numbers used in this study.

\begin{tabular}{|c|c|c|}
\hline Name of protein & Species & Accession no. \\
\hline GsSerp1 & Gnathostoma spinigerum & MK128410 \\
\hline GsSerp2 & G. spinigerum & MK128411 \\
\hline GsSerp3 & G. spinigerum & MK128412 \\
\hline GsSerp4 & G. spinigerum & MK128413 \\
\hline GsSerp5 & G. spinigerum & MK128414 \\
\hline GsSerp6 & G. spinigerum & MK128415 \\
\hline GsSerp7 & G. spinigerum & MK128416 \\
\hline GsSerp8 & G. spinigerum & MK128417 \\
\hline GsSerp9 & G. spinigerum & MK128418 \\
\hline GsSerp10 & G. spinigerum & MK128419 \\
\hline GsSerp11 & G. spinigerum & MK128420 \\
\hline AniSerp & Anisakis simplex & CBX25525.1 \\
\hline TcSerp & Toxocara canis & KHN72316.1 \\
\hline AcnSerp & Ancylostoma caninum & RCN49152.1 \\
\hline AcySerp & A. ceylanicum & EPB78059.1 \\
\hline TtSerp & Trichuris trichiura & CDW55271.1 \\
\hline TsSerp & Trichinella spiralis & CBX25723.1 \\
\hline NaSerp & Necator americanus & ETN83761.1 \\
\hline BmSerp & Brugia malayi & AAB65745.1 \\
\hline AsSerp & Ascaris suum & AEH42098.1 \\
\hline CsSerp & Clonorchis sinensis & ADI60059.1 \\
\hline OvSerp & Opisthorchis viverrini & OON15112.1 \\
\hline SmSerp & Schistosoma mansoni & CCD60352.1 \\
\hline SjSerp & S. japonicum & AAK57435.1 \\
\hline SjSerpB6 & S. japonicum & CAX69453.1 \\
\hline ShSerpB4 & S. haematobium & KGB37772.1 \\
\hline ShSerpB9 & S. haematobium & KGB42280.1 \\
\hline FhSerp & Fasciola hepatica & PIS86324.1 \\
\hline HmSerp & Hymenolepis microstoma & CDS31921.1 \\
\hline EmSerp & Echinococcus multilocularis & CDS35970.1 \\
\hline EgSerp & E. granulosus & CDS22753.1 \\
\hline EhSerp & Entamoeba histolytica & EAL44876.1 \\
\hline TgSerp & Toxoplasma gondii & CEL78311.1 \\
\hline GlSerp1 & Giardia lamblia & XP_001706503.1 \\
\hline HsSerp & Homo sapiens & CAL47031.1 \\
\hline
\end{tabular}

Regarding the cellular component, most potential classical and non-classical ESPs transcripts were categorized into the integral component of membrane category. Transportationrelated proteins were represented, including sodium-dependent serotonin transporter, organic solute transporter alpha-like protein, putative transporter, and heme transporter hrg-1. In Schistosoma mansoni, a serotonin transporter facilitated the distribution of serotonin into neurons or adjacent glial cells to contribute to parasite movement and muscle contraction. Moreover, the serotonin transporter transported exogenous serotonin, which may have affected the uptake of host-derived serotonin [47]. However, the role of host serotonin on parasite biochemical physiology has not yet been addressed and requires further investigation. Regarding biological processes, the metabolic process and regulation of transcription, DNA templates were the most enriched terms for classical and non-classical ESPs, respectively. Alpha-1,2-mannosidase, a classical ESP, is essential for the synthesis and processing of N-linked glycoproteins [27]. In skin-grafted mice, alpha-1,2-mannosidase was strongly expressed in alloantigen-reactive Treg cells that suppressed allograft rejection [39]. However, the role of exogenous alpha-1,2-mannosidase, especially when derived from helminths, in Treg stimulation has not been determined and should be explored.

The top 50 significant transcripts of potential classical ESPs from aL3Gs included a significant proportion of metalloproteases. This result was consistent with our proteomic analysis of aL3Gs-ESPs, which identified metalloproteases as a predominant protease. In a previous study, metalloproteases secreted from the aL3 of $G$. binucleatum could degrade gelatin, fibronectin, and antibodies and thus might contribute to parasitic tissue invasion, migration, and immune evasion [64]. A 24-kDa protein identified as a matrix metalloprotease has been used for the immunodiagnosis of human gnathostomiasis [29, 63]. Furthermore, proteins involved in carbohydrate and lipid metabolism comprised a significant proportion of the top 50 significant transcripts of non-classical ESPs, as well as the secretomic results. These findings indicate that these proteins not only have roles in the regulation of parasite metabolism but may also be necessary to prepare a microenvironment suitable for growth and colonization in the host. In S. japonicum-infected mice, significant changes were observed in uracil, lipid, and carbohydrate metabolism in association with disease progression and the worm burden [66]. However, both the predicted ESPs and secretomic data included large numbers of proteins with unknown functions (i.e., uncharacterized proteins), which may be a consequence of the lack of a genome database and the inability to clarify these transcripts and achieve reliable annotation. Therefore, a $G$. spinigerum genome project will be set as a research priority as soon as possible.

In 2D-immunomics of aL3Gs-ES, seven protein spots were specifically recognized by $G$. spinigerum-infected human sera, and MS identified the serine protease inhibitor serpin in several spots. Serpins are classified into inhibitor family I4, the largest and most diverse superfamily of protease inhibitors; members of this family have been identified in viruses, microorganisms, plants, and animals [12, 51]. Although serpins mainly inhibit serine proteases, some members can inhibit caspases and papain-liked cysteine proteases. Moreover, some serpins exhibit non-inhibitory functions such as molecular chaperone activity, hormone transportation, or even tumor suppression [36]. Regarding immunodiagnosis, $T$. spiralis serpin exhibited promise as an antigen for the immunodiagnosis of swine trichinosis, and yielded $100 \%$ rates for both sensitivity and specificity [45]. Furthermore, recombinant serpin derived from $S$. mansoni was shown to differentially diagnose $S$. mansoni infection from other related diseases and S. haematobium infection [58]. By contrast, the diagnostic potential of serpin from G. spinigerum (GsSerp) remains unknown, due to a lack of previous identification and characterization. In the aL3Gs transcriptomic database presented herein, 11 GsSerp isoforms were identified and their relationship was analyzed using a phylogenetic tree. The wide range of homologies and categorization of these isoforms into different clades might suggest that these proteins perform multiple functions required for parasite biology, including growth, development, mating, fertilization, and immune evasion. The SjSerp isoforms identified from each developmental stage of $S$. japonicum preferably inhibited different serine proteases; for example, $\mathrm{SjB} 10$ inhibited pancreatic elastase [42], whereas a novel isoform, SjSPI, inhibited 


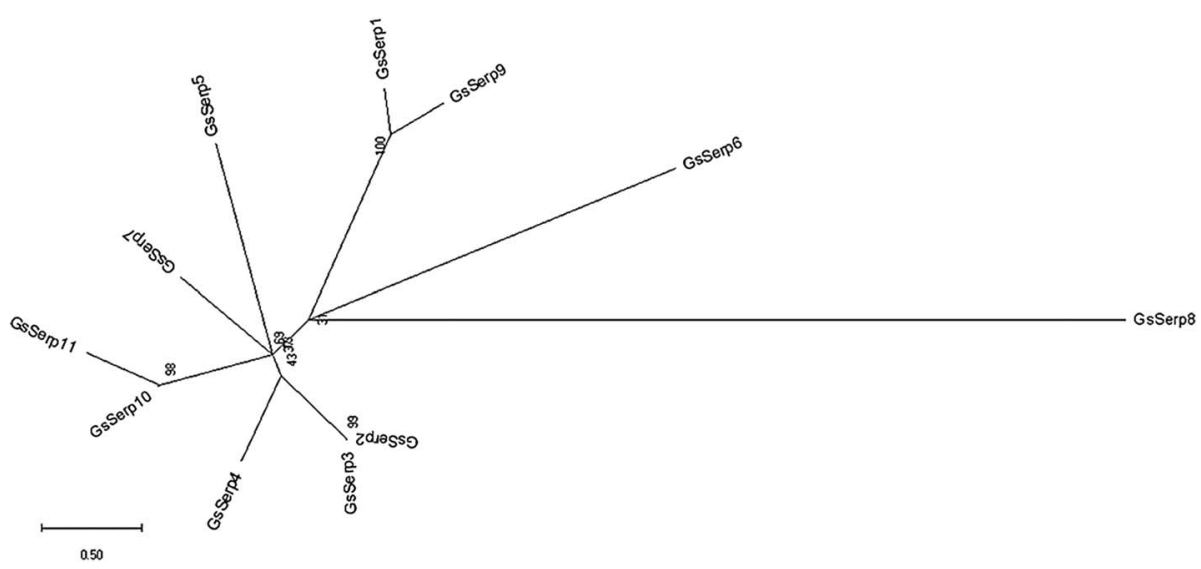

Figure 4. An unrooted maximum likelihood tree showing the genetic relationships among the GsSerp isoforms. The GsSerp isoforms were identified in advanced third-stage larvae of Gnathostoma spinigerum (aL3Gs). The nucleotide and amino acid sequences of GsSerp isoforms were submitted to the NCBI database, and accession numbers are provided in Table 6.

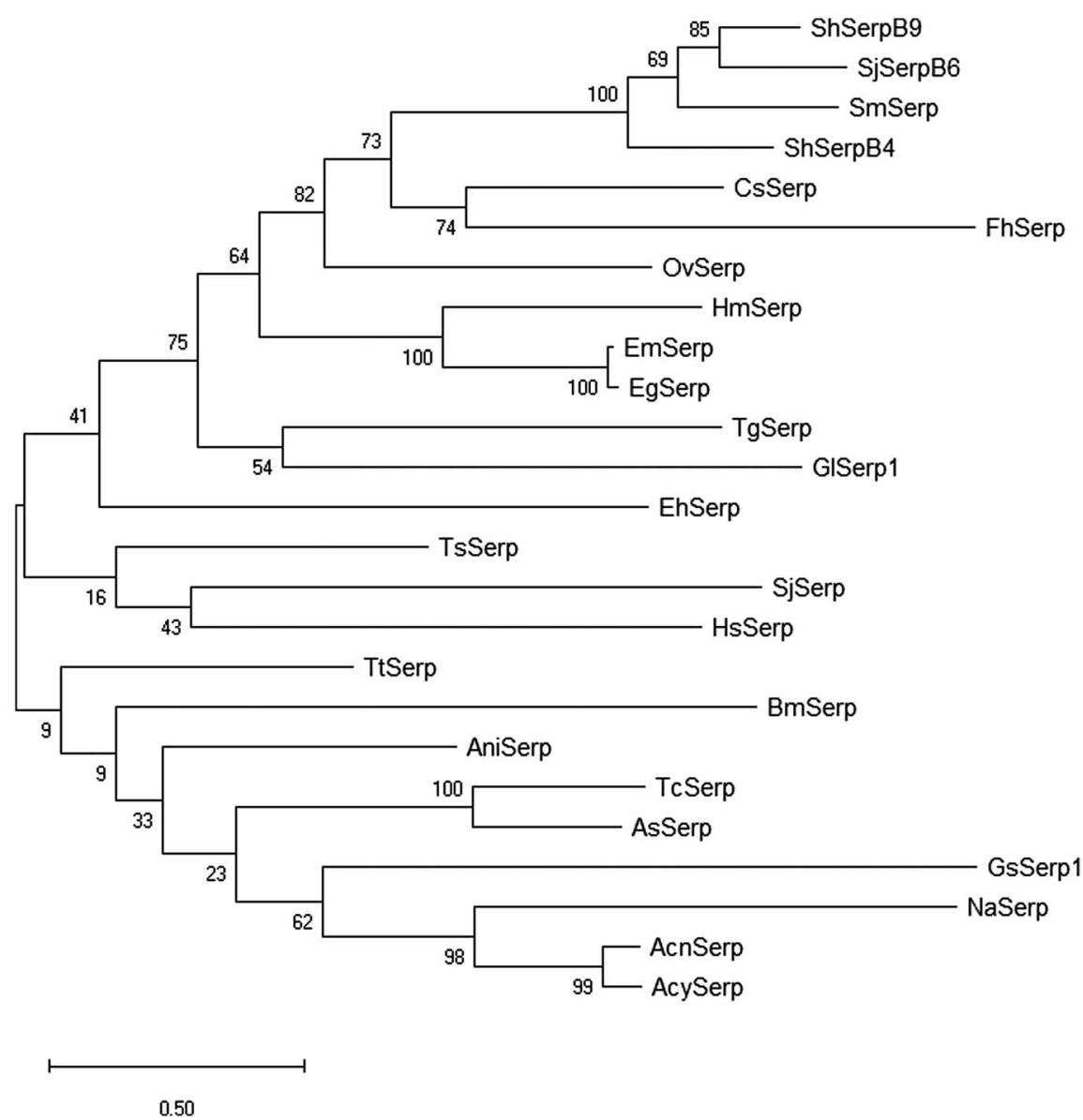

Figure 5. Phylogenetic tree of GsSerp1 and its orthologs. The tree demonstrates the close relationships of GsSerp1 with hookworm and Ascarididae serpins. The accession numbers of GsSerp1 and orthologs included in this analysis are provided in Table 6.

chymotrypsin, trypsin, and thrombin [67]. In S. mansoni, SmSprQ did not inhibit host serine proteases but regulated the homeostasis of cercarial elastase [49].

To predict the immunodiagnostic potential of GsSerp, the amino acid sequence of GsSerp1 was determined following its specific detection by $G$. spinigerum-infected human sera. Subsequently, a multiple alignment and pairwise sequence homology were analyzed to calculate the percent identity and percent similarity of GsSerp1 with the orthologs. The low sequence identity (less than 30\%) between GsSerp1 and its 


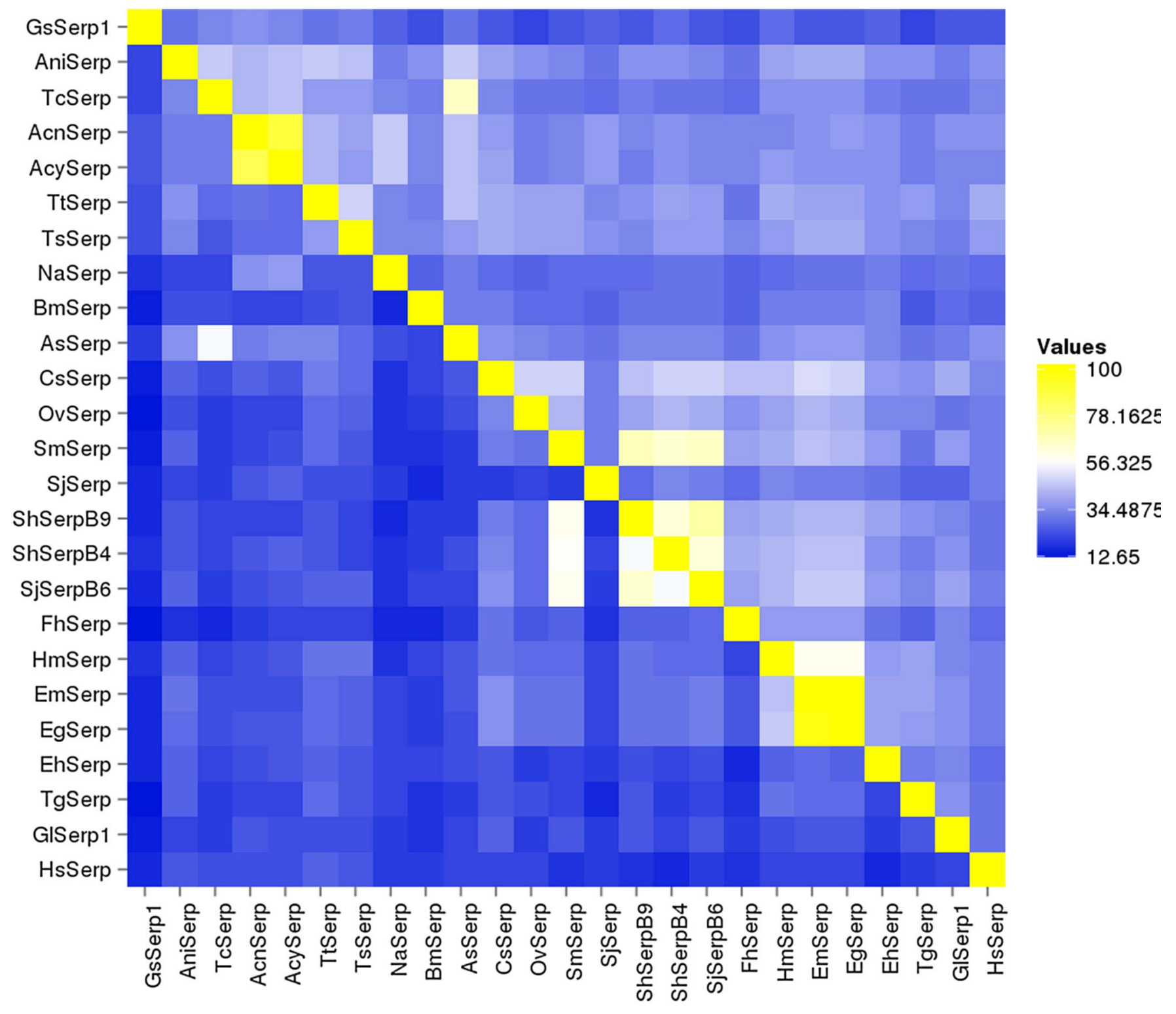

Figure 6. Homology heatmaps. Homology heatmaps for comparisons of the percentage identity (lower left) and similarity (upper right) between GsSerp1 and its orthologs. The percentage identity and similarity values are indicated by different box colors (right).

orthologs indicates that this G. spinigerum antigen is unique and may lead to the development of a reliable immunodiagnostic method. Although serpins derived from other Gnathostoma spp. should be subjected to an analysis, these are not currently available. Future studies will address the production of recombinant GsSerp1 and evaluate immunodiagnostic potential, thus clarifying the capability and reliability of GsSerp1 in this context.

\section{Conclusions}

The transcriptomic database of aL3Gs constructed in this study led to an understanding of basic parasitic molecular biology and the identification of multiple transcripts that may be associated with parasite growth, development, and survival. The predicted ESPs, together with secretomic analysis, have highlighted key biological, physiological, and immunomodulatory molecules that may be indispensable to the parasite life cycle. A 2D-immunomic analysis of aL3Gs-ES identified the serpin GsSerp1 as a promising candidate for the further development of immunodiagnostic protocols. Moreover, the output from an integrated transcriptomics and secretomic analysis not only appears to enhance our understanding of parasite biology, but also facilitates the discovery of novel drugs and vaccines to respectively treat and prevent this harmful type of helminthiasis.

\section{List of abbreviations}

2DE: 2D-gel electrophoresis; aL3Gs: advanced third stage larva of G. spinigerum; CDD: Conserved Domains Database; CDS: Coding sequence; CWA: crude worm antigen; ESPs: 
excretory-secretory proteins; GO: Gene ontology; ML: maximum likelihood analysis; MS: mass spectrometry; NGS: Next-generation sequencing; ORFs: Open reading frames; PE: paired-end; Serpin: serine protease inhibitor; SIAS: Sequence identity and similarity program; SRA: Sequence read archive; UniProt: The universal protein knowledgebase.

\section{Ethics approval and consent to participate}

Helminth-infected human sera and healthy sera used in this study were provided by the Immunodiagnosis for Helminthiasis Unit, Department of Helminthology, Faculty of Tropical Medicine, Mahidol University, under the approval of the Ethics Committee of the Faculty of Tropical Medicine, Mahidol University (no. MUTM 2011-050-01).

\section{Availability of data and materials}

RNA-Seq reads have been deposited in the NCBI-Sequence Read Archive (SRA) database under accession number SRR8137628. This Transcriptome Shotgun Assembly project has been deposited in DDBJ/EMBL/GenBank under the accession number GHIZ00000000. The version described in this paper is the first version, GHIZ01000000. Mass spectrophotometric data were submitted to the PRIDE database. Data are available via ProteomeXchange with identifier PXD013551.

\section{Competing interests}

The authors declare that they have no competing interests.

\section{Authors” contributions}

SN and PAD conceived and designed the study. SN, OR, OP, PM and PAD performed the experiments. SN, OR, OP, PC and PAD analyzed the data. SN, OR, OP and PAD drafted the manuscript. PC performed bioinformatics analysis and data management. PD supervised study design, study implementation and manuscript revision. All authors read and approved the final manuscript.

\section{Supplementary Material}

Supplementary material is available at https://www.parasitejournal.org/10.1051/parasite/2019033/olm

Supplementary Table S1. Statistical summary of raw read and detailed information of assembled transcript BLAST annotation (XLSX 9.7 MB).

Supplementary Table S2. Predicted peptide sequences (XLSX 10 MB).

Supplementary Table S3. Predicted peptide sequences (cont.) (XLSX $10 \mathrm{MB}$ ).

Supplementary Table S4. Potential functional proteins among classical and non-classical excretory-secretory proteins from the advanced third-stage larvae of Gnathostoma spinigerum (aL3Gs) transcriptome (XLSX 290 KB).
Supplementary Figure S1. The quality and quantity of the total RNA sample (PDF $522 \mathrm{~KB}$ ).

Supplementary Figure S2. Bioinformatics workflow of the excretory-secretory proteins (PDF $110 \mathrm{~KB}$ ).

Supplementary Figure S3. Base quality distribution of the read lengths (PDF $849 \mathrm{~KB}$ ).

Supplementary Figure S4. Density (smoothed frequency) of the contigs according to the length of the advanced third-stage larvae of the Gnathostoma spinigerum (aL3Gs) data set (PDF $145 \mathrm{~KB})$.

Supplementary Figure S5. Species distribution of BLAST hits against the UniProt database (PDF $212 \mathrm{~KB}$ ).

Supplementary Figure S6. E-value of the identity distribution (PDF $152 \mathrm{~KB}$ ).

Supplementary Figure S7. Top 20 enriched gene ontology (GO) terms among advanced third-stage larvae of Gnathostoma spinigerum (aL3Gs) transcripts (PDF $233 \mathrm{~KB}$ ).

Acknowledgements. This study was supported by an FTM grant (Fiscal Year 2013) through Supaporn Nuamtanong, FTM grantResearch and Innovation Excellence through Poom Adisakwattana (Fiscal Year 2016), and ICTM Grants from the Faculty of Tropical Medicine, Mahidol University. We gratefully thank the Faculty of Tropical Medicine, Mahidol University for supporting all facilities and services. Our gratitude also goes to the Central Equipment Unit, Faculty of Tropical Medicine, Mahidol University for providing us all necessary instruments.

\section{References}

1. Almeyda-Artigas RJ, Bargues MD, Mas-Coma S. 2000. ITS-2 rDNA sequencing of Gnathostoma species (Nematoda) and elucidation of the species causing human gnathostomiasis in the Americas. Journal of Parasitology, 86, 537-544.

2. Ashburner M, Ball CA, Blake JA, Botstein D, Butler H, Cherry JM, Davis AP, Dolinski K, Dwight SS, Eppig JT, Harris MA, Hill DP, Issel-Tarver L, Kasarskis A, Lewis S, Matese JC, Richardson JE, Ringwald M, Rubin GM, Sherlock G. 2000. Gene ontology: tool for the unification of biology. The Gene Ontology Consortium. Nature Genetics, 25, 25-29.

3. Babiker HA, Abdel-Muhsin AM, Ranford-Cartwright LC, Satti G, Walliker D. 1998. Characteristics of Plasmodium falciparum parasites that survive the lengthy dry season in eastern Sudan where malaria transmission is markedly seasonal. American Journal of Tropical Medicine and Hygiene, 59, 582-590.

4. Bendtsen JD, Jensen LJ, Blom N, von Heijne G, Brunak S. 2004. Feature-based prediction of non-classical and leaderless protein secretion. Protein Engineering, Design and Selection, 17, 349-356.

5. Bendtsen JD, Nielsen H, von Heijne G, Brunak S. 2004. Improved prediction of signal peptides: SignalP 3.0. Journal of Molecular Biology, 340, 783-795.

6. Benjathummarak S, Kumsiri R, Nuamtanong S, Kalambaheti T, Waikagul J, Viseshakul N, Maneerat Y. 2016. Third-stage Gnathostoma spinigerum larva excretory secretory antigens modulate function of $\mathrm{Fc}$ gamma receptor I-mediated monocytes in peripheral blood mononuclear cell culture. Tropical Medicine and Health, 44, 5.

7. Boongird P, Phuapradit P, Siridej N, Chirachariyavej T, Chuahirun S, Vejjajiva A. 1977. Neurological manifestations of gnathostomiasis. Journal of the Neurological Sciences, 31, 279-291. 
8. Brumlik MJ, Pandeswara S, Ludwig SM, Murthy K, Curiel TJ. 2011. Parasite mitogen-activated protein kinases as drug discovery targets to treat human protozoan pathogens. Journal of Signal Transduction, 2011, 971968.

9. Camacho C, Coulouris G, Avagyan V, Ma N, Papadopoulos J, Bealer K, Madden TL. 2009. BLAST+: architecture and applications. BMC Bioinformatics, 10, 421.

10. Chai JY, Sohn WM, Na BK, Park JB, Jeoung HG, Hoang EH, Htoon TT, Tin HH. 2015. Larval Gnathostoma spinigerum detected in Asian swamp eels, Monopterus albus, purchased from a local market in Yangon, Myanmar. Korean Journal of Parasitology, 53, 619-625.

11. Chang Z, Li G, Liu J, Zhang Y, Ashby C, Liu D, Cramer CL, Huang X. 2015. Bridger: a new framework for de novo transcriptome assembly using RNA-seq data. Genome Biology, 16,30 .

12. Chen PY, Chang WS, Chou RH, Lai YK, Lin SC, Chi CY, Wu CW. 2007. Two non-homologous brain diseases-related genes, SERPINI1 and PDCD10, are tightly linked by an asymmetric bidirectional promoter in an evolutionarily conserved manner. BMC Molecular Biology, 8, 2.

13. Chen W, Wang X, Li X, Lv X, Zhou C, Deng C, Lei H, Men J, Fan Y, Liang C, Yu X. 2011. Molecular characterization of cathepsin B from Clonorchis sinensis excretory/secretory products and assessment of its potential for serodiagnosis of clonorchiasis. Parasites \& Vectors, 4, 149.

14. Chernin E. 1992. The early British and American journals of tropical medicine and hygiene: an informal survey. Medical History, 36, 70-83.

15. Chitanondh H, Rosen L. 1967. Fatal eosinophilic encephalomyelitis caused by the nematode Gnathostoma spinigerum. American Journal of Tropical Medicine and Hygiene, 16, 638-645.

16. Cole RA, Choudhury A, Nico LG, Griffin KM. 2014. Gnathostoma spinigerum in live Asian Swamp Eels (Monopterus spp.) from food markets and wild populations, United States. Emerging Infectious Diseases, 20, 634-642.

17. Daengsvang S. 1980. A monograph on the genus Gnathostoma and gnathostomiasis in Thailand. Southeast Asian Medical Information Center: Tokyo, Japan. p. 85.

18. Dahl SG, Sylte I, Ravna AW. 2004. Structures and models of transporter proteins. Journal of Pharmacology and Experimental Therapeutics, 309, 853-860.

19. El Ridi R, Salah M, Wagih A, William H, Tallima H, El Shafie MH, Abdel Khalek T, El Amir A, Abo Ammou FF, Motawi H. 2007. Fasciola gigantica excretory-secretory products for immunodiagnosis and prevention of sheep fasciolosis. Veterinary Parasitology, 149, 219-228.

20. Emanuelsson O, Brunak S, von Heijne G, Nielsen H. 2007. Locating proteins in the cell using TargetP, SignalP and related tools. Nature Protocols, 2, 953-971.

21. Emanuelsson O, Nielsen H, Brunak S, von Heijne G. 2000. Predicting subcellular localization of proteins based on their Nterminal amino acid sequence. Journal of Molecular Biology, 300, 1005-1016.

22. Garg G, Ranganathan S. 2011. In silico secretome analysis approach for next generation sequencing transcriptomic data. BMC Genomics, 12, S14.

23. Garg G, Ranganathan S. 2012. Helminth secretome database (HSD): a collection of helminth excretory/secretory proteins predicted from expressed sequence tags (ESTs). BMC Genomics, $13, \mathrm{~S} 8$.

24. Grainger JR, Smith KA, Hewitson JP, McSorley HJ, Harcus Y, Filbey KJ, Finney CA, Greenwood EJ, Knox DP, Wilson MS, Belkaid Y, Rudensky AY, Maizels RM. 2010. Helminth secretions induce de novo $\mathrm{T}$ cell Foxp3 expression and regulatory function through the TGF- $\beta$ pathway. Journal of Experimental Medicine, 207, 2331-2341.

25. Gupta G, Oghumu S, Satoskar AR. 2013. Mechanisms of immune evasion in leishmaniasis. Advances in Applied Microbiology, 82, 155-184.

26. Herman JS, Chiodini PL. 2009. Gnathostomiasis, another emerging imported disease. Clinical Microbiology Reviews, 22, 484-492.

27. Herscovics A. 2001. Structure and function of Class I alpha 1,2mannosidases involved in glycoprotein synthesis and endoplasmic reticulum quality control. Biochimie, 8, 757-762.

28. Intapan PM, Maleewong W, Sukeepaisarnjaroen W, Morakote N. 2010. An enzyme-linked immunosorbent assay as screening tool for human intestinal capillariasis. Southeast Asian Journal of Tropical Medicine and Public Health, 41, 298-305.

29. Janwan P, Intapan PM, Yamasaki H, Laummaunwai $P$, Sawanyawisuth K, Wongkham C, Tayapiwatana C, Kitkhuandee A, Lulitanond V, Nawa Y, Maleewong W. 2013. Application of recombinant Gnathostoma spinigerum matrix metalloproteinase-like protein for serodiagnosis of human gnathostomiasis by immunoblotting. American Journal of Tropical Medicine and Hygiene, 89, 63-67.

30. Junghae M, Raynes JG. 2002. Activation of p38 mitogenactivated protein kinase attenuates Leishmania donovani infection in macrophages. Infection and Immunity, 70, 5026-5035.

31. Katchanov J, Sawanyawisuth K, Chotmongkoi V, Nawa Y. 2011. Neurognathostomiasis, a neglected parasitosis of the central nervous system. Emerging Infectious Diseases, 17, 1174-1180.

32. Kim D, Hahn AS, Wu S, Hanson NW, Konwar KM, Hallam SJ. 2015. FragGeneScan+: high-throughput short-read gene prediction. Proceedings of the 2015 IEEE Conference on Computational Intelligence in Bioinformatics and Computational Biology (CIBCB 2015). Niagara Falls: Canada.

33. Ko RC, Ng TF. 1998. Evaluation of excretory/secretory products of larval Taenia solium as diagnostic antigens for porcine and human cysticercosis. Journal of Helminthology, 72, 147-154.

34. Kumar S, Stecher G, Li M, Knyaz C, Tamura K. 2018. MEGA $\mathrm{X}$ : Molecular evolutionary genetics analysis across computing platforms. Molecular Biology and Evolution, 35, 1547-1549.

35. Laummaunwai P, Sawanyawisuth K, Intapan PM, Chotmongkol V, Wongkham C, Maleewong W. 2007. Evaluation of human IgG class and subclass antibodies to a $24 \mathrm{kDa}$ antigenic component of Gnathostoma spinigerum for the serodiagnosis of gnathostomiasis. Parasitology Research, 101, 703-708.

36. Law RH, Zhang Q, McGowan S, Buckle AM, Silverman GA, Wong W, Rosado CJ, Langendorf CG, Pike RN, Bird PI, Whisstock JC. 2006. An overview of the serpin superfamily. Genome Biology, 7, 216.

37. Li BW, Wang Z, Rush AC, Mitreva M, Weil GJ. 2012. Transcription profiling reveals stage- and function-dependent expression patterns in the filarial nematode Brugia malayi. BMC Genomics, 13, 184

38. Liu GH, Shao R, Cai XQ, Li WW, Zhu XQ. 2015. Gnathostoma spinigerum mitochondrial genome sequence: a novel gene arrangement and its phylogenetic position within the Class Chromadorea. Scientific Reports, 5, 12691.

39. Long ET, Baker S, Oliveira V, Sawitzki B, Wood KJ. 2010. Alpha-1,2-mannosidase and hence $\mathrm{N}$-glycosylation are required for regulatory $\mathrm{T}$ cell migration and allograft tolerance in mice. PLoS One, 5, e8894.

40. Maleewong W, Wongkham C, Intapan $\mathrm{P}$, Mahaisavariya $\mathrm{P}$, Danseegaew W, Pipitgool V, Morakote N. 1992. Detection of circulating parasite antigens in murine gnathostomiasis by a 
two-site enzyme-linked immunosorbent assay. American Journal of Tropical Medicine and Hygiene, 46, 80-84.

41. Marchler-Bauer A, Bryant SH. 2004. CD-Search: protein domain annotations on the fly. Nucleic Acids Research, 32, W327-331.

42. Molehin AJ, Gobert GN, Driguez P, McManus DP. 2014. Functional characterization of $\mathrm{SjB} 10$, an intracellular serpin from Schistosoma japonicum. Parasitology, 141, 1746-1760.

43. Moore DA, McCroddan J, Dekumyoy P, Chiodini PL. 2003. Gnathostomiasis: an emerging imported disease. Emerging Infectious Diseases, 9, 647-650.

44. Nopparatana C, Tapchaisri P, Setasubun P, Chaicumpa W, Dekumyoy P. 1988. Antibody responses in human gnathostomiasis. Southeast Asian Journal of Tropical Medicine and Public Health, 19, 219-224.

45. Nuamtanong S, Dekumyoy P, Adisakwattana P. 2012. Evaluation of recombinant serine protease inhibitor from Trichinella spiralis for immunodiagnosis of swine trichinosis. Southeast Asian Journal of Tropical Medicine and Public Health, 43, 1094-1104.

46. Pan W, Shen Y, Han X, Wang Y, Liu H, Jiang Y, Zhang Y, Wang Y, Xu Y, Cao J. 2014. Transcriptome profiles of the protoscoleces of Echinococcus granulosus reveal that excretorysecretory products are essential to metabolic adaptation. PLoS Neglected Tropical Diseases, 8, e3392.

47. Patocka N, Ribeiro P. 2013. The functional role of a serotonin transporter in Schistosoma mansoni elucidated through immunolocalization and RNA interference (RNAi). Molecular and Biochemical Parasitology, 187, 32-42.

48. Pearson G, Robinson F, Beers Gibson T, Xu BE, Karandikar M, Berman K, Cobb MH. 2001. Mitogen-activated protein (MAP) kinase pathways: regulation and physiological functions. Endocrine Reviews, 22, 153-183.

49. Quezada LA, Sajid M, Lim KC, McKerrow JH. 2012. A blood fluke serine protease inhibitor regulates an endogenous larval elastase. Journal of Biological Chemistry, 287, 7074-7083.

50. Rana SB, Zadlock FJ, Zhang Z, Murphy WR, Bentivegna CS. 2016. Comparison of de novo transcriptome assemblers and k-mer strategies using the killifish, Fundulus heteroclitus. PLoS One, 11, e0153104.

51. Rawlings ND, Tolle DP, Barrett AJ. 2004. MEROPS: the peptidase database. Nucleic Acids Research, 32, 160-164.

52. Robert-Gangneux F, Creuzet C, Dupouy-Camet J, Roisin MP. 2000. Involvement of the mitogen-activated protein (MAP) kinase signalling pathway in host cell invasion by Toxoplasma gondii. Parasite, 7, 95-101.

53. Rojekittikhun W, Chaiyasith T, Nuamtanong S, Pubampen S, Maipanich W, Tungtrongchitr R. 2002. Gnathostoma infection in Nakhon Nayok and Prachin Buri, Central Thailand. Southeast Asian Journal of Tropical Medicine and Public Health, 33, 474484.

54. Saksirisampant W, Chawengkiattikul R, Kraivichain K, Nuchprayoon S. 2001. Specific IgE antibody responses to somatic and excretory-secretory antigens of third stage G. spinigerum larvae in human gnathostomiasis. Journal of the Medical Association of Thailand, 84, S173-S181.
55. Schroeder A, Mueller O, Stocker S, Salowsky R, Leiber M, Gassmann M, Lightfoot S, Menzel W, Granzow M, Ragg T. 2006. The RIN: an RNA integrity number for assigning integrity values to RNA measurements. BMC Molecular Biology, 7, 3.

56. Soares-Silva M, Diniz FF, Gomes GN, Bahia D. 2016. The mitogen-activated protein kinase (MAPK) pathway: role in immune evasion by trypanosomatids. Frontiers in Microbiology, $7,183$.

57. Sun GG, Wang ZQ, Liu CY, Jiang P, Liu RD, Wen H, Qi X, Wang L, Cui J. 2015. Early serodiagnosis of trichinellosis by ELISA using excretory-secretory antigens of Trichinella spiralis adult worms. Parasites \& Vectors, 8, 484.

58. Tanigawa C, Fujii Y, Miura M, Nzou SM, Mwangi AW, Nagi S, Hamano S, Njenga SM, Mbanefo EC, Hirayama K, Mwau M, Kaneko S. 2015. Species-specific serological detection for schistosomiasis by serine protease inhibitor (SERPIN) in multiplex assay. PLoS Neglected Tropical Diseases, 9, e0004021.

59. Thiangtrongjit T, Adisakwattana $\mathrm{P}$, Limpanont $\mathrm{Y}$, Dekumyoy $\mathrm{P}$, Nuamtanong S, Chusongsang P, Chusongsang Y, Reamtong O. 2018. Proteomic and immunomic analysis of Schistosoma mekongi egg proteins. Experimental Parasitology, 191, 88-96.

60. Thuwajit C, Thuwajit P, Kaewkes S, Sripa B, Uchida K, Miwa M, Wongkham S. 2004. Increased cell proliferation of mouse fibroblast NIH-3T3 in vitro induced by excretory/secretory product(s) from Opisthorchis viverrini. Parasitology, 129, 455-464.

61. Thuwajit C, Thuwajit P, Uchida K, Daorueang D, Kaewkes S, Wongkham S, Miwa M. 2006. Gene expression profiling defined pathways correlated with fibroblast cell proliferation induced by Opisthorchis viverrini excretory/secretory product. World Journal of Gastroenterology, 12, 3585-3592.

62. Tort J, Brindley PJ, Knox D, Wolfe KH, Dalton JP. 1999. Proteinases and associated genes of parasitic helminths. Advances in Parasitology, 43, 161-266.

63. Uparanukraw P, Morakote N, Harnnoi T, Dantrakool A. 2001. Molecular cloning of a gene encoding matrix metalloproteinaselike protein from Gnathostoma spinigerum. Parasitology Research, 87, 751-757.

64. Vibanco-pérez N, Durán-avelar MDJ, Zambrano-zaragoza JF, Ventura-ramón GH. 2015. Proteases secreted by Gnathostoma binucleatum degrade fibronectin and antibodies from mammals. Helminthologia, 52, 6-10.

65. Visudhiphan $\mathrm{P}$, Chiemchanya $\mathrm{S}$, Somburanasin $\mathrm{R}$, Dheandhanoo D. 1980. Causes of spontaneous subarachnoid hemorrhage in Thai infants and children. A study of 56 patients. Journal of Neurosurgery, 53, 185-187.

66. Wu J, Xu W, Ming Z, Dong H, Tang H, Wang Y. 2010. Metabolic changes reveal the development of schistosomiasis in mice. PLoS Neglected Tropical Diseases, 4, e807.

67. Zhang Y, Guo J, He L, Zong HY, Cai GB. 2018. Isolation and characterization of a novel serine protease inhibitor, SjSPI, from Schistosoma japonicum. Parasitology International, 67, 415-424.

68. Zheng WH, Västermark Å, Shlykov MA, Reddy V, Sun EI, Saier MH Jr. 2013. Evolutionary relationships of ATP-Binding Cassette (ABC) uptake porters. BMC Microbiology, 13, 98.

Cite this article as: Nuamtanong S, Reamtong O, Phuphisut O, Chotsiri P, Malaithong P, Dekumyoy P \& Adisakwattana P. 2019. Transcriptome and excretory-secretory proteome of infective-stage larvae of the nematode Gnathostoma spinigerum reveal potential immunodiagnostic targets for development. Parasite 26, 34. 
Reviews, articles and short notes may be submitted. Fields include, but are not limited to: general, medical and veterinary parasitology; morphology, including ultrastructure; parasite systematics, including entomology, acarology, helminthology and protistology, and molecular analyses; molecular biology and biochemistry; immunology of parasitic diseases; host-parasite relationships; ecology and life history of parasites; epidemiology; therapeutics; new diagnostic tools.

All papers in Parasite are published in English. Manuscripts should have a broad interest and must not have been published or submitted elsewhere. No limit is imposed on the length of manuscripts.

Parasite (open-access) continues Parasite (print and online editions, 1994-2012) and Annales de Parasitologie Humaine et Comparée (1923-1993) and is the official journal of the Société Française de Parasitologie. 